Aus der Abteilung Klinische Neurophysiologie

(Prof. Dr. med. W. Paulus)

im Zentrum Neurologische Medizin

der Medizinischen Fakultät der Universität Göttingen

\title{
Die Wirkung des BDNF-Polymorphismus auf transkraniell induzierte Neuroplastizität
}

INAUGURAL - DISSERTATION

zur Erlangung des Doktorgrades

der Medizinischen Fakultät

der Georg-August-Universität zu Göttingen

vorgelegt von

Driss BOURAKKADI ZARROUKI

aus

Meknes/Marokko

Göttingen 2012 
Dekan: Prof. Dr. med. M. P. Schön

I. Berichterstatterin: Prof. Dr. rer. nat. A. Antal

II. Berichterstatter: Prof. Dr. med. Schulze

III. Berichterstatter: Prof. Dr. med. Gruber

Tag der mündlichen Prüfung: 11.02.2013 


\section{Inhaltverzeichnis}

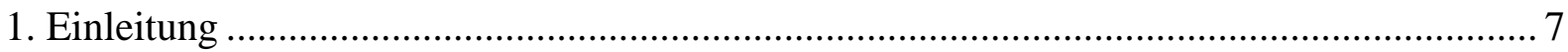

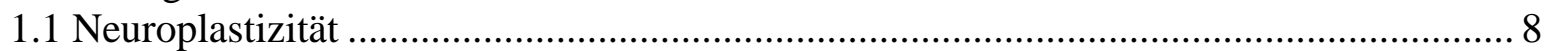

1.2 Entstehung von Langzeitpotenzierung (LTP) ..................................................... 9

1.3 Einfluss genetischer Faktoren auf Neuroplastizität und Lernen .................................. 10

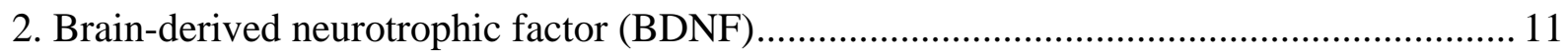

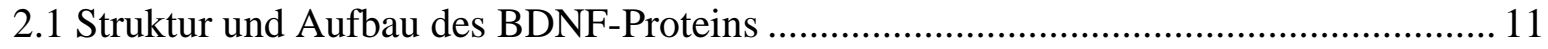

2.2 Transport, Sekretion und Signaltransduktion des BDNF-Proteins ............................... 11

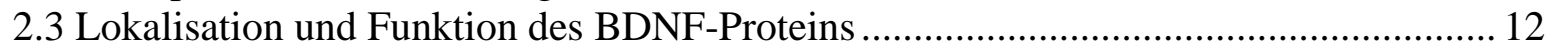

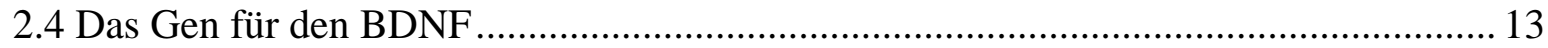

2.5 Funktion des BDNF und des BDNF-Gens in der Neuroplastizität und im Lernen......... 14

2.6 Die Rolle des BDNF in neurologischen und psychiatrischen Erkrankungen............15

2.7 Der Val66Met-Polymorphismus des BDNF-Gens (rs6265) ......................................... 16

2.8 Einfluss des BDNF-Polymorphismus Val66Met auf die Lernfähigkeit und das

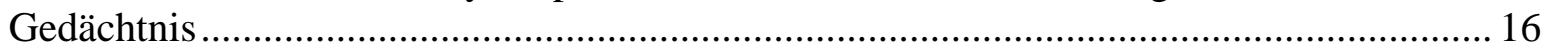

3. Die Auslösung von LTP-ähnlicher synaptischer Plastizität mittels transkranieller

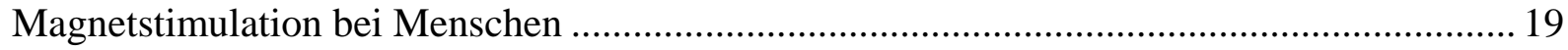

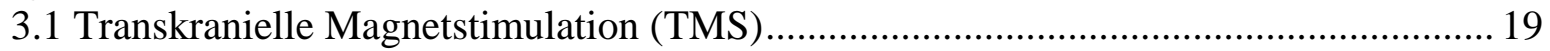

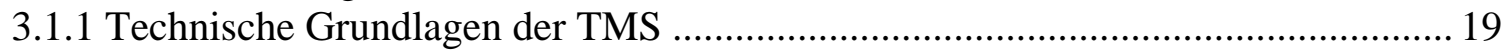

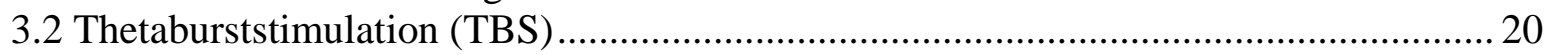

4. Transkranielle elektrische Stimulation............................................................................ 21

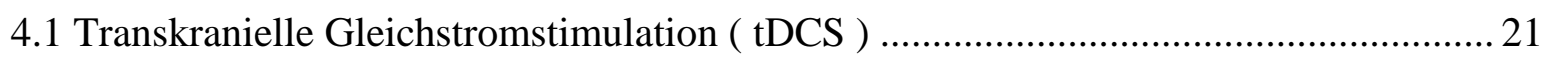

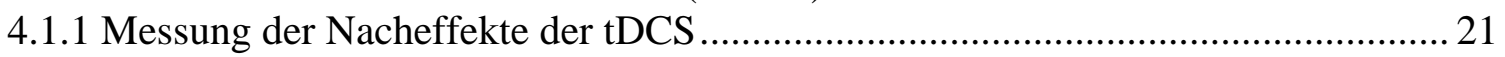

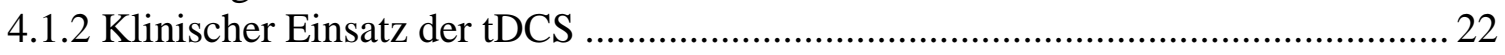

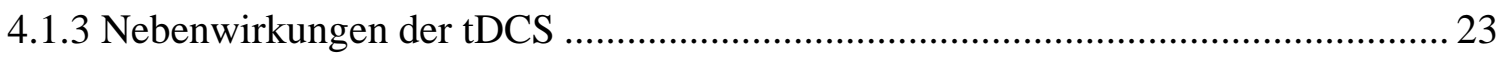

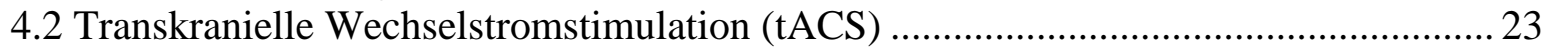

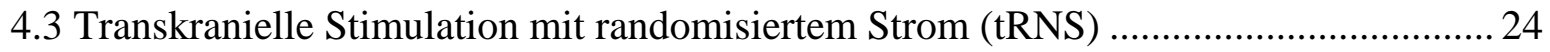

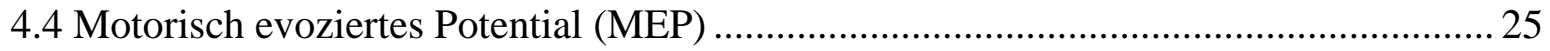

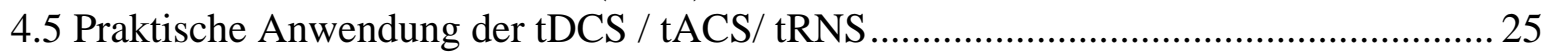

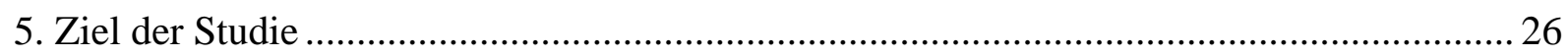

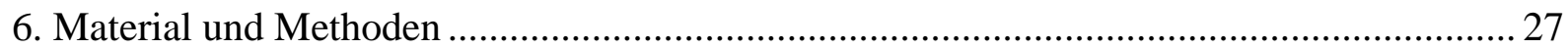

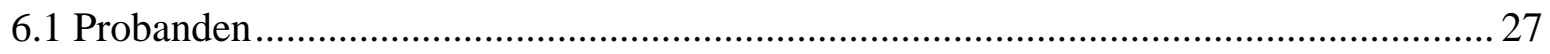

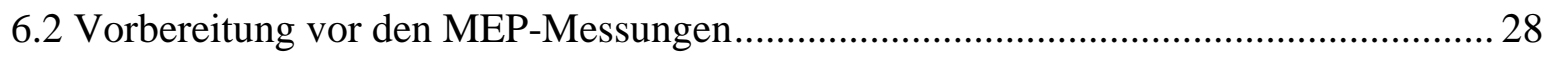

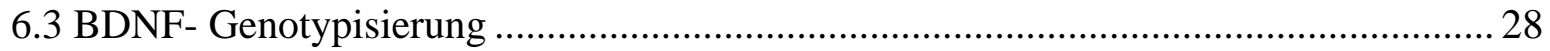

6.4 Elektrische und magnetische Stimulation: tRNS, tACS, tDCS und iTBS .................... 28

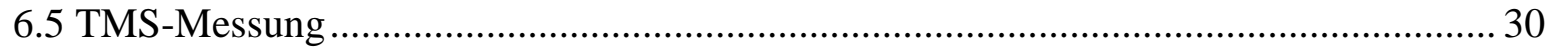

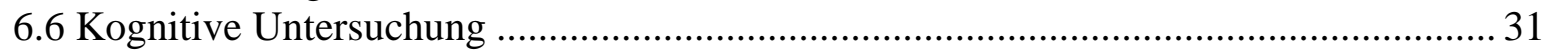

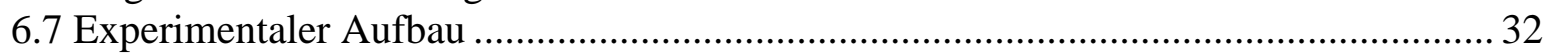

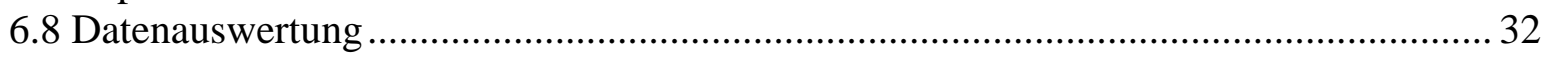

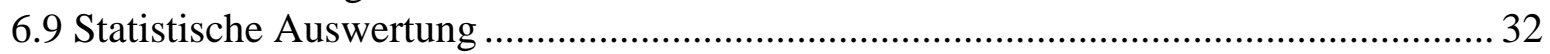

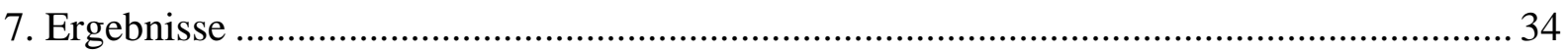

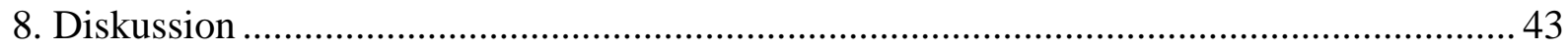




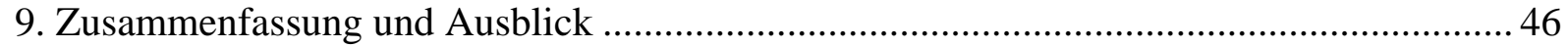

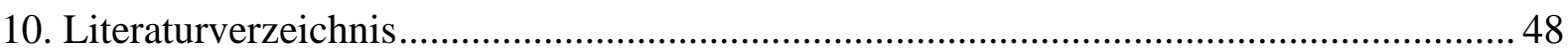

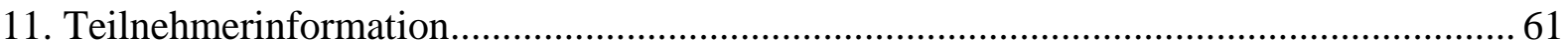




\section{Abkürzungsverzeichnis}

ADHS Aufmerksamkeitsdefizit- und Hyperaktivitätsstörung

ADM Musculus abductor digiti minimi

Ag Silber

AgCl Silberchlorid

AMT aktive motorische Reizschwelle

ANOVA Analysis of Variance (Varianzanalyse)

BDNF Brain-derived neurotrophic factor

cAMP zyklisches Adenosinmonophosphat

COMT Catechol-O-methyltransferase

cTBS kontinuierliche Thetaburststimulation

DLPFC dorsolateraler präfrontaler Kortex

EMG Elektromyografie

EPSP Exzitatorische postsynaptische Potentiale

FDI Musculus interosseus dorsalis I

fMRT funktionelle Magnetresonanztomografie

GABA $\quad \gamma$-Aminobuttersäure

iTBS intermittierende Thetaburststimulation

LTD long-term depression (Langzeithemmung)

LTP long-term potentiation (Langzeitpotenzierung)

M1 primär-motorische Kortex

mBDNF reifer Brain-derived neurotrophic factor

MEP Motorisch evozierte Potentiale

Met Methionin

MRT Magnetresonanztomografie

MSAP Muskelsummenaktionspotential

NMDA N-Methyl-D-Aspartat

PAS gepaarte assoziative Stimulation

PCR Polymerasen-Kettenreaktion

PFC präfrontaler Kortex

PLC-y Phospholipase C

proBDNF Brain-derived neurotrophic factor (Vorläufer)

RFLP Restriction Fragment Length Polymorphism 
rTMS repetitive transkranielle Magnetstimulation

sps Abtastrate

sTMS single pulse transkranielle Magnetstimulation

TBS theta burst stimulation

tDCS transkranielle Gleichstromstimulation

TES transkranielle elektrische Stimulation

TMS transkranielle Magnetstimulation

TrkB Tyrosinkinase-B-Rezeptor

tRNS transkranielle Rauschstromstimulation

Val Valin

ZNS Zentralnevensystem 


\section{Einleitung}

Die Bedeutung transkranieller elektrischer und magnetischer Stimulationsverfahren nimmt insofern zu, als dass konzeptionelle Verständnisgerüste verfeinert werden. Die Grundlagenforschung bietet damit einen stetig verbesserten Rahmen für die klinische Anwendung. Die Option der nichtinvasiven, gezielten und schmerzlosen Stimulation des zerebralen Kortex eröffnet eine Vielzahl von therapeutischen Perspektiven.

Die aktuell am häufigsten angewendete Methode zur Beeinflussung der Exzitabiltät des motorischen Kortex (M1) ist die repetitive transkranielle Magnetstimulation (rTMS) (Übersicht zum Beispiel in Ziemann et al. 2008). Historisch wurde die transkranielle Magnetstimulation (TMS) zum ersten Mal von Barker und seinen Kollegen beim Menschen angewendet (Barker et al. 1985). Die rTMS ermöglicht jedoch nicht nur die Modulation, sondern auch die Messung der Kortexexzitabilität mittels Einzel- oder Doppelpuls (single or double pulse) -TMS und erlaubt dadurch auch die Überprüfung der Effektivität der rTMS und auch anderer interventioneller transkranieller Stimulationsmethoden. Für die Erweiterung und für die bessere Beeinflussung der Kortexexzitabilität benutzt man die theta burst stimulation (TBS) als Sonderform der rTMS (Huang et al. 2005). Man unterscheidet zwischen der kontinuierlichen theta burst Stimulation (cTBS) und der intermittierenden theta burst Stimulation (iTBS). Die cTBS führt zu einer signifikanten Hemmung der kortikalen Exzitabilität (Di Lazzaro et al. 2005). Die iTBS hat dagegen einen faszilitatorischen Effekt auf die kortikale Aktivität (Huang et al. 2005). Es existieren mittlerweile verschiedene Studien, die den Effekt der iTBS auf neurologische Erkrankungen untersuchen.

Auch andere Ansätze erlauben die Induktion von Plastizität. Die transkranielle Gleichstromstimulation (tDCS, direct current stimulation) bewirkt eine Änderung der neuronalen Membranspannung und damit u.a. der Spontanaktivität von pyramidalen Projektionsneuronen (Creutzfeldt et al. 1962, Bindman et al. 1964). Die kortikale Exzitabilität wird bei anodaler tDCS gesteigert, bei kathodaler tDCS reduziert (Nitsche und Paulus 2000, 2001, Nitsche et al. 2003).

Die transkranielle Wechselstromstimulation (tACS, alternating current stimulation) ist eine neuere Technik (Antal et al. 2008). Während der tACS wird ein Wechselstrom mit Frequenzbereichen von derzeit $0.1 \mathrm{~Hz}$ bis $5 \mathrm{kHz}$ auf dem Kortex appliziert. Die tACS intendiert mit ihrer Eigenschaft der oszillierenden Stimulation die Interferenz mit kortikalen Oszillationen. Eine weitere Option zur Interferenz ist die transkranielle Rauschstimulation (tRNS, random noise stimulation). Die tRNS kann ebenfalls bei 10 Minuten anhaltender 
Stimulation eine Erhöhung der Exzitabilität von M1 über die Stimulation hinaus erzielen (Terney et al. 2008).

Weiteres Ziel der wissenschaftlichen Arbeiten auf diesem Gebiet ist die Optimierung dieser Techniken für potentielle therapeutische Anwendungen bei ansonsten pharmakoresistenten neurologischen Erkrankungen. Richtungspunkt dieser Untersuchungen ist es darüber hinaus, interindividuelle, insbesondere genetisch bedingte Varianzen besser zu verstehen. Cheeran et al. (2008) zeigten, dass die Methionin-Allel-Träger des BDNF-Gens (brain-derived neurotrophic factor) nicht auf die spezielle Form der rTMS, die TBS, reagieren im Vergleich zu den Trägern der Valin66Valin-Variante. Der BDNF gehört zu der Gruppe der Neurotrophine und reguliert das Überleben der Zellen, die Proliferation und das Wachstum der Synapsen im zentralen Nervensystem. Der BDNF beeinflusst aber auch funktionell Neuronenerregbarkeit und synaptische Plastizität und spielt damit eine Rolle als Mediator in der Langzeit-Potenzierung und der aktivitätsabhängigen Plastizität.

In dieser Promotionsarbeit wurde die Auswirkung der Genotypisierung einer großen Anzahl von Probanden auf kortikale Plastizität durchgeführt, speziell auf den Effekt des BDNFPolymorphismus in Abhängigkeit von diversen Stimulationsprotokollen. Der Unterschied zwischen Val- und Met-Allel-Trägern sowie deren Reaktion auf die tDCS, tACS, tRNS und TBS bei der Auslösung motorisch evozierter Potentiale (MEP) stand hierbei im Vordergrund. Weiterhin analysieren wir die Rolle des BDNF-Polymorphismus in kognitiven Aufgaben.

\subsection{Neuroplastizität}

Man nennt die Eigenschaft neuronaler Netzwerke, sich abhängig von ihrer Aktivität zu verändern, neuronale Plastizität. Sowohl Synapsen als auch die damit verknüpften Neuronen und Hirnareale können sich je nach bestehenden Anforderungen anpassen (Sanes und Donoghue 2000). In der Neuroplastizität sind kurzfristige und langfristige Veränderungen zu differenzieren. Zu den kurzfristigen zählt die Reorganisation des Kortex innerhalb von Minuten auf der Basis funktioneller Veränderungen. Hier entstehen zum Beispiel neue Gleichgewichte zwischen Erregung und Hemmung im Sinne sogenannter homöostatischer Plastizität. Spannungsabhängige Ionenkanäle sind an der Änderung der Membranerregbarkeit beteiligt. Die schnell eintretende Amelioration der Funktion schon bestehender Synapsen nennt man Langzeitpotenzierung (LTP, long-term potentiation), die Verschlechterung Langzeitdepression (LTD, long-term depression). Längerfristige Änderungen der Neuroplastizität erfordern längere Zeiträume. $\mathrm{Zu}$ diesen Änderungen zählen die Synapsenneubildung und das so genannte „Sprouting“ (Hattori et al. 1990). Unter dem 
Begriff Sprouting versteht man das Aufsprossen von neuen Axonendigungen, an denen neue Synapsen sich ausbilden. Eine Reorganisation des kortikalen Homunculus ist zum Beispiel eine vieluntersuchte Folge einer peripheren Denervierung.

Neuroplastizität lässt sich auf verschiedenen Ebenen betrachten. Man spricht zum Beispiel von synaptischer Plastizität, wenn man sich auf die zelluläre Ebene der einzelnen Neuronen bezieht. Wenn man sich dagegen auf größere funktionelle Netzwerke bezieht, spricht man von kortikaler Plastizität (Lovden et al. 2010, Pearson-Fuhrhop et al. 2009). Das Gedächtnis stellt eine Form systemischer Neuroplastizität dar, auf der Basis von Neubildung oder Verstärkung synaptischer Verbindungen (Pinel 2001).

Die Untersuchung der menschlichen Plastizität des primären motorischen Kortex durch TMS gilt als besonders effiziente Methode.

\subsection{Entstehung von Langzeitpotenzierung (LTP)}

Auf Hebb geht die Hypothese zurück, dass aktivitätsabhängige verknüpfte Veränderung der synaptischen Übertragung zwischen den Nervenzellen die Grundlage für menschliches Lernen und Gedächtnisbildung darstellen (Hebb 1949). Dementsprechend bewirkt jede ins zentrale Nervensystem eingehende Lernerfahrung ein charakteristisches Muster von neuronaler Aktivität, in der Regel kodiert in Aktionspotentialsequenzen, in einer bestimmten Anzahl von Zellen innerhalb von ständig neu verknüpften Netzwerken. Die Aktivität wird zum Beispiel wiederholt über die synaptischen Verbindungen der beteiligten Neuronen übertragen (Reverberationskreise) und führt so $\mathrm{zu}$ einer Verbesserung der synaptischen Informationsübertragung. Die Folgen sind morphologische Veränderungen der Synapsen und deren Gesamtzahl (Cooke und Bliss 2006).

Bei der LTP stellen N-Methyl-D-Aspartat-Rezeptoren (NMDA) einen wichtigen Mechanismus dar. NMDA-Rezeptoren sind in Form von Ionenkanälen in der postsynaptischen Membran lokalisiert. Durch Andockung von Glutamat aus der präsynaptischen Membran werden die NMDA-Rezeptoren aktiviert. Diese Aktivierung bewirkt einen Einstrom von Calciumionen. Im Normalfall besteht allerdings eine Blockade durch Magnesiumionen. Nur bei einer Teildepolarisation der postsynaptischen Membran wird die Magnesiumblockade aufgehoben und somit eine mögliche Öffnung der Calciumkanäle. Daher ist eine Aktivierung der NMDA-Rezeptoren nur bei konvergierender Stimulation der prä- und postsynaptischen Membran oder bei hochfrequenter und wiederholter Depolarisation der postsynaptischen Nervenzelle möglich (Kandel et al. 1996). 
Wichtige Eigenschaften der LTP sind ihre Assoziativität und ihre Input-Spezifität. Letztere bedeutet, dass die Verstärkung nur eine bestimmte synaptische Verbindung betrifft, ohne Einflussnahme auf die umliegenden, möglicherweise nicht aktivierten Neuronen. Mit Assoziativität ist gemeint, dass eine einzelne Erregung nicht ausreicht, eine LTP auszulösen (Hebbsche Lernregel, Hebb 1949). Wenn das afferente Signal eines präsynaptischen Neurons auf die postsynaptische Membran nach Auslösung eines EPSP (Exzitatorische postsynaptische Potentiale) trifft, tritt dann der gegenteilige Effekt der Potenzierung, die Depression, auf. Diese vermindert die synaptische Übertragung zwischen den Neuronen. Langfristige Depression wird in Entsprechung zur LTP als LTD betrachtet.

\subsection{Einfluss genetischer Faktoren auf Neuroplastizität und Lernen}

Eine Vielzahl von Genen weist eine gezielte Beeinflussung der Neuroplastizität und des Lernens auf. Beispielsweise seien hier erwähnt das Gen des BDNF (Hariri et al. 2003, Egan et al. 2003), die Catechol-O-methyltransferase (COMT; de Frias et al. 2010), das Apolipoprotein E (APO E4; Bertram et al. 2007) und das Kibra-Gen (Papassotiropoulos et al. 2006, Schaper et al. 2008). Im Tiermodell können verschiedene Knockoutvarianten gezüchtet werden und somit die Beeinflussung der Produktion unterschiedlicher Proteine. Bei Menschen ist die Untersuchung natürlicher auftretender genetischer Veränderungen möglich. Durch Mutation bestimmter Genstellen und den Ersatz eines Basenpaares durch ein anderes entsteht der so genannte „Single nucleotide polymorphism“ (SNP). Das abweichend entstehende Protein zeigt veränderte chemische und strukturelle Eigenschaften und so eine Modifikation seiner Funktionalität (z.B. ein schnellerer Zerfall des Moleküls durch verminderte Hitzestabilität im Falle des COMT-Val158Met-Polymorphismus). Wenn das Protein an Gedächtnisprozessen beteiligt ist, kann ein SNP sich nachteilig auf die Lernfähigkeit auswirken (Egan et al. 2003, Erickson et al. 2008, Papassotiropoulos et al. 2006).

Diese Arbeit beschäftigt sich mit dem BDNF-Polymorphismus, der vermutlich das Ansprechen von Probanden und Patienten auf externe Stimulationsmethoden besonders stark beeinflusst. 


\section{Brain-derived neurotrophic factor (BDNF)}

\subsection{Struktur und Aufbau des BDNF-Proteins}

Hinsichtlich seines Aufbaus und seiner Struktur ist der BDNF der Gruppe der Neurotrophine zuzuordnen. Im Jahre 1982 wurde er als ein Wachstumsfaktor mit neurotropher Aktivität aus Schweinehirnen extrahiert. Hierauf ist die Bezeichnung BDNF zurückzuführen (Barde et al. 1982). Neurotrophine sind als Nervenwachstumsfaktoren im zentralen Nervensystem (ZNS) und der Peripherie des Nervensystems zu finden. Der nerve growth factor (NGF) sowie die Neurotrophine 3-6 (NT3 bis NT6) gehören dieser Gruppe ebenfalls an. Strukturchemisch gesehen ist BDNF ein Homodimer, welches aus 2 Monomeren mit ca. 240 Aminosäuren besteht. Jedes Monomer besteht wiederum aus 7 ß-Strängen. Diese sind mit drei lösungsexponierten Haarnadelschleifen und einer längeren Schleife verbunden und enthalten drei Disulfidbrücken zwischen den Cystein-Aminosäuren. Kennzeichnend für die Dimere ist, dass sie parallel liegen und nichtkovalent (hydrophob) zusammengehalten werden (Laske und Eschweiler 2006).

\subsection{Transport, Sekretion und Signaltransduktion des BDNF-Proteins}

Assoziiert ist die Genfamilie der Neurotrophine mit den Tyrosinkinase-Rezeptoren (Chen CM et al. 2007). Letztere lassen sich sowohl während der pränatalen Entwicklungsphase, als auch im adulten Nervensystem finden (Muragaki et al. 1995). Durch Bindung an diese Rezeptoren und Ablaufen einer komplexen intrazellulären Signalkaskade (Chen CM et al. 2007) erfolgt die Aktivierung der Proteinbiosynthese und eine vermehrte Kalziumpermeabilität der Zellmembran (Reichardt und Farinas 1997).

Das Vorläuferprotein von BDNF (proBDNF) ist ein 32 kB schweres Protein, welches aus 382 Aminosäuren besteht, selektiv an Mikrotubuli mit Hilfe von Huntingtin transportiert, in Vesikel verpackt und aktivitätsabhängig ausgeschüttet wird (Mowla et al. 2001). Weiterhin ist zu erwähnen, dass das größere proBDNF intrazellulär stabiler als BDNF ist. Die Pro-Region beinhaltet wahrscheinlich eine Differenzierungssequenz und erfüllt die Aufgabe, BDNF zielgenau zu sortieren. Die Ausschüttung von proBDNF erfolgt aktivitätsabhängig. Während proBDNF überwiegend an den niedrigaffinen Tyrosinkinase-B-Rezeptor (p75NT-Rezeptor) bindet, bindet BDNF an den hochaffinen Tyrosinkinase-B-Rezeptor (TrkB-Rezeptor) (Lee R et al. 2001). Die Bindung an den TrkB-Rezeptor ruft Signalkaskaden hervor. Diese beeinflussen die Gentranskription und die zelluläre Proteinsynthese ( $\mathrm{Li}$ et al. 1998). Extrazellulär wird proBDNF im synaptischen Spalt von Proteasen wie Plasmin zu BDNF 
gespalten (Lee R et al. 2001). Plasmin ist ein wichtiger Modulator der BDNF-Aktivität. Es entsteht infolge der Spaltung von Plasminogen durch den Gewebe-Plasminogen-Aktivator (tPA) (Calabresi et al. 2000). Im Tiermodell konnte gezeigt werden, dass die Umwandlung von proBDNF zu BDNF eine LTP hippokampaler Neuronen herbeiführt. Dies fungiert als Zellmodell für die Bildung von Langzeitgedächtnis (Pang et al. 2004).

Die intrazelluläre Signaltransduktion, welche durch die Bindung von BDNF an seinen TrkBRezeptor zustande kommt, führt zur Trk-Dimerisierung und Aktivierung der TyrosinkinaseAktivität. Die ligandenvermittelte Aggregation der Rezeptoren führt zur Autophosphorylierung intrazellulärer Domänen. Letztere bewirken eine Aktivierung von Signalmolekülen, wie der Phospholipase C (PLC-y), der Phosphadityl-Inositol-3-Kinase (PI3Kinase) und des Adapterproteins Shc. Die weitere Signalkaskade hat einen Einfluss auf die zelluläre Gentranskription und Proteinsynthese (Greene und Kaplan 1995). Dieser Mechanismus der Neurotrophinwirkung kann Stunden bis Tage andauern. Es gibt jedoch auch innerhalb von Minuten auftretende Neurotrophinwirkungen, die nur kurz anhalten und die synaptische Transmission beeinflussen (Levine et al. 1996). Es wird angenommen, dass hier keine Änderungen in der Genexpression auftreten (Henneberger et al. 2002). Als wahrscheinlicher Signalweg werden der schnelle PLC-y-vermittelte Anstieg von Diacylglycerol (DAG) und Inositoltriphosphat (IP3) sowie die damit verbundene Steigerung der Kalziumkonzentration angesehen.

Darüber hinaus wurde eine andere schnelle Wirkung nach Aktivierung der TrkB-Rezeptoren dargelegt, welche Neurotrophinen erstmals ähnliche funktionelle Eigenschaften wie konventionell erregenden Transmittern zuschreibt (Kafitz et al. 1999). Als mögliche Ursache für diesen Effekt wird eine Interaktion des TrkB-Rezeptors mit einem Natriumkanal betrachtet (Blum et al. 2002). So kann BDNF anhand von an TrkB-Rezeptoren gekoppelten Natriumkanälen postsynaptische Membranen depolarisieren (Korte 2004).

\subsection{Lokalisation und Funktion des BDNF-Proteins}

Eine wesentliche Funktion von Neurotrophinen besteht darin, die Proliferation, die Kollateralisierung, das Axonwachstum und die dendritische Arborisation der Neurone zu stimulieren. Die Bildung von BDNF geschieht in der Peripherie des Nervensystems, insbesondere in Neuronen (Zafra et al. 1991) sowie in Schwannzellen peripherer Motoneurone (Acheson et al. 1991). BDNF wird im zentralen Nervensystem unter anderem von den Gliazellen hergestellt (Leibrock et al. 1989). Die Verteilung von BDNF im zentralen 
Nervensystem ist ubiquitär. BDNF ist in Neuronen des embryonalen, postpartalen und adulten ZNS vorhanden. Im Hippokampus ist die höchste Konzentration von BDNF zu finden. Untersuchungen zeigen, dass die Bildung von BDNF ebenfalls in Herz, Lunge, Thrombozyten (Rosenthal et al. 1991), Lymphozyten, Monozyten, Muskelzellen und Fibroblasten erfolgt (Cartwright et al. 1994). Weiterhin wird BDNF in den Epithelien des Gastrointestinaltraktes (Zunge, Ösophagus, Duodenum und Kolon) sowie des Urogenitaltraktes (Niere, Urothel, Blasenepithel, Eileiter und Uterusendothel) produziert (Lommatzsch et al. 1999). Hochaffine TrkB-Rezeptoren sind in den Epithelien nicht vorhanden. Sie lassen sich hingegen in den zugehörigen viszeralen Ganglien finden, wo das Epithel nur als BDNF-Quelle und die Neurone als Ziel zu dienen hat.

An Rattengehirnkulturen konnte gezeigt werden, dass BDNF bei cholinergen Zellen einen positiven Einfluss auf die neuronale Überlebensrate und die Aktivität der Cholinacetyltransferase (ChAT) hat (Alderson et al. 1990, Nonomura und Hatanaka 1992).

Im Tierversuch konnte gezeigt werden, dass BDNF zur Verstärkung der Freisetzung von $\gamma$ Aminobuttersäure (GABA), Dopamin, Acetylcholin (ACh), Glutamat und Serotonin dienen kann (Sala et al. 1998, Goggi et al. 2002, Yamada et al. 2004).

\subsection{Das Gen für den BDNF}

Das BDNF-Gen befindet sich auf dem Chromosom 11p12 und modelliert als Translationsprodukt das BDNF-Protein. Nach neuen Erkenntnissen erstreckt sich das BDNFGen über ca. 70 kB. Das BDNF-Gen setzt sich aus elf teilweise alternativen Exons und neun funktionalen Promotern zusammen. Diese sind je nach Gewebe- und Gehirnregion spezifisch nutzbar. Untersuchungen zeigen, dass sich die Translation des BDNF-Gens auf das letzte Exon begrenzt (Exon IX). Zwei Exons können nur in Kombination mit Exon V benutzt werden. Die Exons II, III, IV, V und VI können nicht in ein Translationsprodukt übersetzt werden. Das Translationsprodukt umfasst jene Exons beginnend vom ATG-Codon in Exon IX (Pruunsild et al. 2007).

Das Gen BDNFOS, welches 2005 entdeckt wurde, beteiligt sich am komplexen Transkriptionsvorgang des BDNG-Gens. Hierbei produziert dieses Gen alternativ gespleißte Antisensetranskripte (alternatively spliced natural antisense transcripts). Es findet eine Überlappung statt zwischen einem Exon des BDNFOS und einem Exon des BDNF (Liu et al. 2006). Es setzt sich aus zehn Exons zusammen und erstreckt sich über $191 \mathrm{kB}$. Die 
Regulation des Transkriptionsproduktes des BDNF-Gens ist je nach Gewebeart die wichtige Funktion des BDNFOS (Pruunsild et al. 2007).

\subsection{Funktion des BDNF und des BDNF-Gens in der Neuroplastizität und im Lernen}

BDNF beeinflusst die Hirnentwicklung (Chen CM et al. 2007) und die aktivitätsabhängige synaptische Plastizität sowie eine dem Lernen und Gedächtnis zugrunde liegende LTP (Laske und Eschweiler 2006). Die BDNF-mRNA-Konzentration im dorsalen präfrontalen Kortex (DPFC) weist einen Anstieg von der Kindheit zum jungen Erwachsenenalter auf. Gleichzeitig tritt eine strukturelle und funktionelle Entwicklung des frontalen Kortex auf (Webster et al. 2002).

Der BDNF ist genauso wichtig für das Gehirn des Erwachsenen, weil er die Prozesse der neuronalen Plastizität beeinflusst: der BNDF beeinflusst direkt die zellulären Prozesse neuronaler Plastizität, indirekt wirkt er auf andere Prozesse ein, die wiederrum die Plastizität modifizieren, beispielsweise bei affektiven Störungen wie Depression. Die BDNF-Rezeptoren befinden sich insbesondere in gedächtnisrelevanten Hirnregionen wie dem PFC und im Hippokampus (Cunha et al. 2010). Als Folge neuronaler Aktivität wird der BDNF vermehrt ausgeschüttet (Egan et al. 2003). Die synaptische Plastizität und die Lernprozesse werden durch Modifikation synaptischer Verbindungen sowohl exzitatorischer als auch inhibitorischer Synapsen unterstützt. Der BDNF unterstützt kurzfristig die Potenzierung synaptischer Erregungsübertragung durch die Depolarisation postsynaptischer Nervenzellen und erleichtert die Ausschüttung präsynaptischer Neurotransmitter. Langfristig bewirkt der BDNF eine anhaltende Veränderung der Neuronenerregbarkeit und der synaptischen Plastizität (Pearson-Fuhrhop et al. 2009). Dadurch nimmt der BDNF eine wichtige Mediatorfunktion bei der LTP und der aktivitätsabhängigen Plastizität ein.

Der BDNF reguliert die Transkription von mehreren Faktoren, die die kognitive Funktion beeinflussen (Finkbeiner et al. 1997) sowie die Ausschüttung von Neurotransmittern (Bolton et al. 2000). Der BDNF ist zum Beispiel in der Lage, eine schnelle Potenzierung der glutamatvermittelten synaptischen Übertragung zu erzielen (Lessmann und Heumann 1998). Die BDNF-mRNA ist im Hippokampus bei Lernprozessen erhöht (Patterson et al. 2001).

Die BDNF-Konzentration im Gehirn und im Serum lässt sich durch unterschiedliche Faktoren beeinflussen. Während Stress diese Konzentration beschränkt, tragen andere Faktoren wie etwa Lernprozesse, verschiedene antidepressive Therapiemodalitäten und körperliche Aktivität zu deren Erhöhung bei. Es ist anzunehmen, dass die Bestimmung des BDNF- 
Serumspiegels in Zukunft an diagnostischer Bedeutung und therapeutischer Wichtigkeit hinsichtlich psychiatrischer Krankheitsbilder gewinnen würde (Laske und Eschweiler 2006).

Im Tierversuch an Mäusen wurde gezeigt, dass das Ausschalten des BDNF-Gens oder postpartal des Rezeptors für BDNF das Lernverhalten der Tiere stark einschränkt. Dies weist auf die Funktion des BDNF und TrkB-Rezeptors bei aktivitätsabhängiger synaptischer Plastizität hin, bei der einige Lernvorgänge maßgeblich beeinflusst werden. Es ist anzumerken, dass die als Voraussetzung für das Langzeitgedächtnis zu betrachtende Langzeitpotenzierung bei genetisch veränderten Mäusen mit ausgeschaltetem BDNF-Gen oder ohne TrkB-Rezeptor kräftig beschränkt ist (Korte 2004).

In anderen Studien an BDNF-Knockout-Mäusen wird geschildert, dass die Mäuse eine hochgradige Störung bei der Entwicklung des Nervensystems und eine verkürzte Lebenserwartung aufweisen. Die Tiere, die das Erwachsenenalter überhaupt erreicht haben, zeigen ein Defizit des räumlichen Lernens und eine verminderte LTP-Entstehung (Linnarsson et al. 1997). Eine Blockade der BNDF-Aktivität im Hippokampus führt zum Ausbleiben der induzierten Lernverbesserung durch physisches Training (Vaynman und Gomez-Pinilla 2006). Die kognitiven Defizite, die durch Inhibition des BDNF entstehen, zeigen eine volle oder teilweise Reversibilität, wenn eine exogene BDNF-Gabe im Anschluss erfolgt (PearsonFuhrhop et al. 2009).

\subsection{Die Rolle des BDNF in neurologischen und psychiatrischen Erkrankungen}

Eine mögliche Ursache für die Degeneration von Nervenzellen könnte ein Defizit an bestimmten Neurotrophinen sein. Die Entstehung von verschiedenen neurodegenerativen Erkrankungen, beispielsweise dem Morbus Parkinson, Morbus Alzheimer und der amyotrophischen Lateralsklerose, könnte mit neurotrophen Faktoren in Zusammenhang gebracht werden (Schulte-Herbrüggen et al. 2007). Bei der multiplen Sklerose handelt es sich um eine fehlerhafte Reaktion der zellulären Immunantwort. Interessant dabei ist die Ausschüttung von BDNF von den Immunzellen beim Entzündungsprozess. Ein direkter Zusammenhang zwischen der Sekretion von BDNF aus den Immunzellen und der Stärke der Entzündungsaktivität bei Patienten mit Multipler Sklerose konnte gezeigt werden (WeinstockGuttman et al. 2007). 


\subsection{Der Val66Met-Polymorphismus des BDNF-Gens (rs6265)}

Der SNP beim BDNF-Gen ist ein Austauschpolymorphismus zwischen Guanin und Adenin und führt zum Valin-zu-Methionin-Austausch in der Region 5' im Codon 66(Val66Met) auf dem Chromosom 11p13. Er ist im BDNF-Gen im Exon 9 positioniert (Huang et al. 2005). Das BDNF-Protein selbst ist nicht vom SNP betroffen, sondern sein Vorläufer proBDNF, aus dem der reife BDNF (mBDNF) gebildet wird (Seidah et al. 1996). Die Variante Val66Met führt dazu, dass ein niedriger intrazellulärer BDNF-Spiegel und eine reduzierte aktivitätsabhängige BDNF-Sekretion vorhanden sind (Egan et al. 2003). Durch die defekte Bildung eines Transportsignals ist die Sekretion des BDNF gestört. Dadurch wird zwar nicht weniger BDNF produziert, aber in geringerem Maße aus der Zelle freigesetzt (Chen $\mathrm{J}$ et al. 2004). Chen Z-Y et al. (2005) wiesen eine gestörte Interaktion des BDNF-Moleküls mit einem Transportprotein, dem Sortilin, nach.

\subsection{Einfluss des BDNF-Polymorphismus Val66Met auf die Lernfähigkeit und das}

\section{Gedächtnis}

Der Val66Met-Polymorphismus hat einen Effekt auf den intrazellulären Transport und Sekretion des BDNF in Nervenzellen. In tierexperimentellen Untersuchungen hatte die MetBDNF-Variante in Neuronen des Hippokampus einen störenden Effekt auf intrazellulären Transport und Sekretion von BDNF. Dies führt zu einer Reduzierung der LTP (Egan et al. 2003).

Bei der Untersuchung des Hirnvolumens mittels Magnetresonanztomographie (MRT) bei verschiedenen Ethnien zeigte sich eine kortikale Volumenreduktion beidseitig im Hippokampus und DLPFC bei Trägern des Met-Allels im Vergleich zu Trägern des Val/ValAllels (Pezawas et al. 2004).

In einer anderen Studie wurden die fluide Intelligenz, die mathematische Rechenleistung und das Erinnerungsvermögen geprüft. Bei Trägern des Met-Allels war die Leistung in allen durchgeführten Aufgaben schlechter. Weiterhin konnte mittels MRT eine Verkleinerung des Hippokampus um 3.9 bis 5\% bei Trägern des Met-Allels im Vergleich zu Nicht-Met-AllelTrägern anschaulich gemacht werden (Miyajima et al. 2008). Ebenso sind reduzierte Volumina des Hippokampus und des PFC bei Trägern des Met-Allels zu beobachten (Chen J et al. 2004, Pezawas et al. 2004). Hariri et al. (2003) fanden eine reduzierte Aktivierung des Hippokampus während der Enkodierung und dem Wiedererkennen von nicht-verbalen deklarativen Lerninhalten. Träger des Met-Allels zeigen im Gegenteil zu Nicht-Met-Allel- 
Trägern eine verminderte deklarative Lern- und Gedächtnisleistung (Egan et al. 2003, Goldberg et al. 2008, Hariri et al. 2003). Eine verminderte Lernfähigkeit konnte bei Trägern des Met-Allels, wenn sie nicht-deklarative, motorische Lernaufgaben bekommen, gezeigt werden (Fritsch et al. 2010). Weiterhin wurde berichtet, dass diese Träger eine größere Tendenz zu Fehlerangabe und ein schlechteres Behalten des motorischen Lernerfolgs nach ein paar Tagen aufweisen (McHughen et al. 2010). Harris et al. (2006) fanden dagegen eine ähnliche Leistung bei beiden Genotypen in einer verbalen Lernaufgabe (logisches Gedächtnis) bei gesunden älteren Probanden. Nagel et al. (2008) begründeten die unterschiedlichen Ergebnisse in einer eventuellen Interaktion des BDNF Polymorphismus mit anderen SNPs. Außerdem kommt es im Alter zu einer Volumenreduktion in Gehirnstrukturen, wie dem PFC und dem medialen Temporallappen (MTL), welche eine wichtige Rolle in Gedächtnisprozessen spielen. Dies könnte noch ein Grund für die unterschiedlichen Ergebnisse sein (Hedden und Gabrieli 2004). Zusätzlich entstehen altersbedingte Gedächtnisdefizite aufgrund von verminderter Ausschüttung von Dopamin im PFC. In Situationen schwindender Ressourcen ist der Einfluss eines SNP, der für sich schon zu reduzierter kognitiver Leistungsfähigkeit beiträgt, besonders stark (Lindenberger et al. 2008). Dadurch können die Ergebnisse von Untersuchungen desselben SNP bei älteren und jüngeren Probanden variieren.

In den wenigen Studien, in denen die Beziehung zwischen dem BDNF Val66Met und die Auslösung von LTP- und LTD-ähnliche Plastizität untersucht wurden, zeigte sich eine verminderte synaptische Plastizität bei transkranieller Stimulation des M1 (Cheeran et al. 2008, Kleim et al. 2006). Hierbei ist zu erwähnen, dass der Genotyp nicht auf alle verschiedenen Stimulationsprotokolle Einfluss hatte. Cheeran et al. (2008) führten eine elektrische Reizung des N. medianus durch und leiteten dabei die motorisch evozierten Potentiale (MEP) auf den Musculus abductor pollicis brevis ab. Dabei zeigte sich bei beiden BDNF-Genotypen nur ein angedeuteter Unterschied in den MEP-Amplituden. Bei einer während einer motorischen Aufgabe applizierten tDCS, profitierten sowohl Met-Allel-Träger als auch Nicht-Träger gleichermaßen (Fritsch et al. 2010). Antal et al. (2010) kamen zum Ergebnis, dass Val/Val-Träger und Val/Met-Träger unterschiedlich auf die iTBS, tRNS und tDCS reagieren. Die iTBS löste eine Plastizitätsänderung nur bei Val/Val-Trägern aus. Sowohl bei der anodalen als auch bei der kathodalen tDCS zeigten Val/Met-Träger eine Zunahme der Plastizität. Bei der tRNS gab es keinen großen Unterschied zwischen den beiden Gruppen zu verzeichnen. 


\subsection{Der BDNF-Polymorphismus und die Entstehung von bestimmten Krankheiten}

Huang et al. (2007) zeigten, dass drei SNPs (rs 6265, rs11030104 und rs2049045) des BDNFGens eng mit dem Morbus Alzheimer in Verbindung stehen. Ein Defizit an BDNF spielt möglicherweise eine Rolle in der Pathogenese des Morbus Parkinson, denn eine niedrige Menge an BDNF verkürzt die Lebenszeit der dopaminergen Neuronen im Striatum (Chen CM et al. 2007). Wichtig ist, dass der BDNF im Hippokampus einen wichtigen Faktor bei Lernprozessen und Gedächtnisbildung darstellt. Bei der Alzheimer Erkrankung ist der Hippokampus atrophiert und die Produktion der BDNF-mRNA in Neuronen des Hippokampus und des Kortex herabgesetzt (Laske und Eschweiler 2006).

Watanabe et al. (2006) konnten über keinen Zusammenhang zwischen dem Auftreten der Schizophrenie und dem SNP rs6265 berichten. In einer anderen Studie wurde die Val66MetVariante des BDNF-Gens und ihre Verbindung mit der Morphologie des Gehirns, kognitiven Fähigkeiten oder psychiatrischen Erkrankungen von Chao et al. (2007) untersucht. Im Zusammenhang mit der Aufmerksamkeitsdefizit- und Hyperaktivitätsstörung (ADHS) wurden der SNP rs6265 und zwei andere Polymorphismen des BDNF-Gens untersucht. In den Familien, in denen ein Kind an ADHS erkrankt war, konnte eine Verbindung zwischen einem seltenen Halotyp und dieser Erkrankung nachgewiesen werden (Lee J et al. 2007). Schimmelmann et al. (2007) widerlegten den Zusammenhang zwischen ADHS und dem Val66Met-Polymorphismus.

Eine weitere Studie untersuchte die Assoziation zwischen dem Val66Met-Polymorphismus und der Anfälligkeit, an Depression zu erkranken. Träger des Val66Val-Allels zeigten ein höheres Risiko für das Auftreten einer Depression. Wenn die Träger des Val66Val-Allels tatsächlich an Depression erkrankten, zeigten sie bessere exekutive Funktionen und Gedächtnisfunktionen als Träger des Val66Met-Allels (Ribeiro et al. 2007). Träger des Val66Met-Allels sind dagegen emotional stabiler (Laske und Eschweiler 2006).

Zivadinov et al. (2007) untersuchten den Polymorphismus rs6265 und seinen Zusammenhang mit der Morphologie des Gehirns und neurologischen Prüfungen bei Patienten mit multipler Sklerose. Es gab dabei keine positive Assoziation zwischen Trägern des Met-Allels und den neurokognitiven Testverfahren. Hingegen hatten die Patienten mit dem Met-Allel weniger Substanzdefekte in der grauen Substanz. 


\section{Die Auslösung von LTP-ähnlicher synaptischer Plastizität mittels transkranieller}

\section{Magnetstimulation bei Menschen}

\subsection{Transkranielle Magnetstimulation (TMS)}

Die TMS ist ein nichtinvasives Verfahren, das eine externe Stimulation von Neuronen erlaubt und somit eine geeignete Technik für die Untersuchung der LTP bei Menschen darstellt. Diese nicht-invasive Technik ermöglicht die Bewertung der funktionellen Integrität des motorischen Pyramidenbahnsystems. Bei dieser Technik wird eine Spule auf den Kopf des Probanden aufgelegt und durch magnetische Impulse werden bestimmte Kortexareale selektiv stimuliert. Im primären motorischen Kortex M1 werden Neuronenverbände mittels single pulse TMS (sTMS) stimuliert und dadurch wird die Messung der MEPs möglich. Die TMS bietet im Vergleich zur transkraniellen elektrischen Stimulation (TES) (Merton und Morton 1980) eine schmerzfreie und bei gleicher Sensitivität ebenso eine einfache Applikation. Um die Nacheffekte der TMS zu erweitern und so eine Neuromodulation zu erzielen, verwendet man die rTMS. Man unterscheidet zwischen einer niederfrequenten und einer hochfrequenten rTMS. Bei niedrigen Frequenzen bewirkt man eine Hemmung, bei höheren Frequenzen dagegen eine Erhöhung der Kortexexzitabilität (Chen $R$ und Seitz 2001). In pharmakologischen Studien konnte gezeigt werden, dass bestimmte Rezeptoren die Effekte der rTMS beeinflussen können. So wird die durch rTMS induzierte Veränderung der kortikospinalen Exzitabilität bei Gabe von Lorazepam, ein GABA-Rezeptor-Antagonist, oder Dextrometrophan, ein NMDA-Rezeptor-Antagonist, unterdrückt (Fitzgerald et al. 2005).

\subsubsection{Technische Grundlagen der TMS}

Wesentlicher Bestandteil des Magnetstimulators ist ein Kondensator, der mit einer Magnetspule verbunden ist. Durch diesen Pulskondensator baut sich innerhalb von 100-800 $\mu$ s ein Magnetfeld in der Spule auf und wieder ab. Unterhalb der Spule wird ein elektrisches Feld erzeugt. Dieses entsteht durch die zeitliche Veränderung des Magnetfeldes und induziert einen Stromfluss im menschlichen Gewebe. Dadurch wird eine elektrische, schmerzfreie und wiederholbare Stimulation von bestimmten Gehirnarealen extern induziert (Siebner und Ziemann 2007). Mittels TMS kann man Hirnareale, die maximal $2 \mathrm{~cm}$ unterhalb der Schädeloberfläche liegen, stimulieren. Deshalb ist eine Stimulation des Hippokampus, um dort die Entstehung von LTP zu untersuchen, nicht möglich. Ferner bestehen keine Verhaltensmassen, die so selektiv die Hippocampus-Aktivität erfassen würden, als dass eine Erfolgskontrolle oder Monitoring der Stimulation möglich wäre (Cooke und Bliss 2006). Aus 
diesem Grund werden stattdessen Repräsentationsareale bestimmter Handmuskeln im M1 stimuliert und als Kontrolle und Ergebnisparameter werden MEPs der kontralateralen Handmuskeln abgeleitet (Stefan et al. 2000, 2004, Ziemann et al. 2004). Die MEPs werden über Oberflächenelektroden, die über dem Zielmuskel angebracht werden, abgeleitet. Dadurch wird es ermöglicht, eine elektromyographische (EMG) Summerantwort aller motorischen Muskeleinheiten zu erfassen. Die Neuronenverbände leiten die absteigende Erregungsinformation über den kortikospinalen Trakt zum Rückenmarksvorderhorn. Auf dieser Ebene erfolgt die monosynaptische Übertragung auf die $\alpha$-Motoneuronen. Wenn eine ausreichende Anzahl an exzitatorischen postsynaptischen Potentialen (EPSPs) vorhanden ist, werden Aktionspotentiale über periphere Nerven zu der neuromuskulären Endplatte des Zielmuskels weitergeleitet. Als Werkzeug zur Beurteilung der kortikospinalen Exzitabilität verwendet man die Spitze-zu-Spitze MEP-Amplitude.

\subsection{Thetaburststimulation (TBS)}

Die intermittent theta burst stimulation (iTBS) stellt eine relativ neue Sonderform der rTMS dar. Das iTBS-Protokoll (Huang et al. 2005) lehnt sich an ein tierexperimentelles Protokoll zur Induzierung von LTP und LTD an (Larson und Lynch 1986). Das von Huang et al. (2005) entwickelte Protokoll besteht aus drei bursts mit einer Frequenz von $50 \mathrm{~Hz}$ und einer Wiederholung alle $200 \mathrm{~ms}$ (5 Hz). Die kontinuierliche theta burst Stimulation (cTBS) führt zu einer signifikanten Unterdrückung der MEP-Amplituden durch eine spezifische Hemmung eines intrazerebralen Reizkreislaufs (Di Lazzaro et al. 2005). Werden die 8 Sekunden Pause zwischen den Stimulationsblöcken hinzugefügt, bekommt man die iTBS und so einen faszilitatorischen Effekt auf die MEP-Amplituden für eine Dauer von ca. 15-30 Minuten poststimulatorisch (Huang et al. 2005). Die TBS hat einen Erregbarkeitseffekt auf den prämotorischen (Mochizuki et al. 2005) und den visuellen Kortex (Franca et al. 2006). Mittlerweile findet man verschiedene klinische Studien, die neurologische Erkrankungen mittels iTBS behandeln. Talelli et al. (2007) führten iTBS-Sitzungen bei Schlaganfallpatienten mit inkompletter Remission von Paresen der oberen Extremitäten durch. Eine einzelne iTBS-Sitzung (600 Pulse) über der beteiligten Hemisphäre führte zu einer Verbesserung der motorischen Funktion der paretischen Hand. In diesem Fall verbesserte sich die Reaktionszeit für 30 Minuten. Diese Befunde wurden im Vergleich mit Sham- und cTBS-Stimulation durchgeführt. Poreisz et al. (2009) untersuchten Tinnituspatienten mittels iTBS. Diese zeigten keine Besserung der Symptomatik. Die tägliche 
Anwendung der iTBS für 2 Wochen führte zu einer Verbesserung der spastischen Parese der unteren Extremität bei Patienten mit Multipler Sklerose (Mori et al. 2010).

Um die physiologischen Vorgänge des Wirkmechanismus der iTBS, ihre Effektivität und die möglichen klinischen Anwendungen ausreichend zu verstehen, sind weitere Studien nötig.

\section{Transkranielle elektrische Stimulation}

\subsection{Transkranielle Gleichstromstimulation ( tDCS )}

Schon in den 50er- und 60er-Jahren wurde die schwache Gleichstromstimulation in tierexperimentellen Studien zur Erzeugung zerebraler Erregbarkeitsveränderung verwendet (Bindman et al. 1964, Creuzfeldt et al. 1962, Gartside 1968, Purpura und McMurtry 1965). Der zugrunde liegende Mechanismus ist eine Verschiebung des Ruhemembranpotentials in den Neuronenverbänden.

Die transkranielle Gleichstromstimulation ist ein einfaches nichtinvasives Verfahren, bei dem über an der Kopfhaut angebrachte Elektroden ein kontinuierlicher Gleichstrom verabreicht wird. Der transkortikale Gleichstrom führt zu einer unterschwelligen tonischen Auslenkung des Ruhemembranpotentials von kortikalen Neuronen. Folglich nimmt die Häufigkeit spontaner Aktionspotentiale indirekt zu oder ab (Creutzfeldt et al. 1962, Bindman et al. 1964).

Die Stromflussrichtung ist im Hinblick auf die Ausrichtung der Neuronen wichtig für die tDCS-Wirkung. So hat eine Stromflussrichtung quer zur Anordnung eines Neurons nur eine geringe Bedeutung für die Effektivität der tDCS. Im Gegensatz dazu führt ein Stromfluss in Längsrichtung eines Neurons zu einer ausgeprägteren Verschiebung des Potentials entlang seiner Längsachse. Die Dauer der tDCS ist ebenfalls entscheidend dafür, ob und für wie lange eine Veränderung der kortikalen Erregbarkeit anhält. Eine Stimulation von wenigen Sekunden hat keine anhaltenden Effekte nach Beendigung der Stimulation. Dagegen hält die kortikale Erregbarkeitsänderung über eine Stunde an, wenn die tDCS mindestens 9 bis 13 Minuten dauert (Nitsche und Paulus 2000, 2001).

\subsubsection{Messung der Nacheffekte der tDCS}

Die tDCS ermöglicht eine Verschiebung des Ruhemembranpotentials der Neuronenpopulation, ohne dass ein direktes Aktionspotential entsteht. Dadurch wird die Erregbarkeit der kortikalen Neuronen moduliert und indirekt auch deren Spontanaktivität. Die Effekte bzw. Nacheffekte der tDCS können mittels sTMS untersucht werden. Eine 
Darstellung der MEPs, die bei TMS-Reizen entstehen, erlaubt eine Aussage über die Erregbarkeitsänderungen, die die tDCS bewirkt. Dabei nehmen die MEP-Amplituden bei der anodalen tDCS zu, während diese bei der kathodalen tDCS abnehmen (Nitsche und Paulus 2000).

Ältere Studien (Gartside 1968, Islam et al. 1997) zeigten, dass die erhöhte Exzitabilität nach anodaler tDCS von der Proteinsynthese abhängt. Zusätzlich scheinen hier die Modulation des cAMP (cyclic Adenosinmonophosphate), die Veränderung der intrazellulären CalciumKonzentration (Hattori et al. 1990, Islam et al. 1995a) und die frühzeitige Gen-Expression (Islam et al. 1995b) eine wichtige Rolle zu spielen. Bei den Nacheffekten der kathodalen tDCS sind nicht-synaptische Mechanismen basierend auf Änderungen neuronaler Membranfunktion beteiligt (Ardolino et al. 2005).

Der Nacheffekt auf die MEPs wird supprimiert sowohl bei der anodalen als auch bei der kathodalen tDCS bei Applikation eines NMDA-Rezeptorantagonists, beispielsweise Dextromethorphan. Dies kann daher eine Änderung der synaptischen Wirksamkeit der exzitatorischen Projektion innerhalb kortikospinaler Neuronen bewirken (Nitsche et al. 2008). Während der tDCS zeigt Dextromethorphan jedoch keinen Effekt und es wird vermutet, dass die Polarisation der Neuronen eine Schlüsseleigenschaft in dieser Phase repräsentiert. Der Natriumkanal-Antagonist Carbamazepin blockiert die Nacheffekte der anodalen tDCS auf die MEPs während und nach der Stimulation. Dies korreliert mit der Vorstellung, dass die anodale tDCS die Neuronen depolarisiert, indem es einen Natriumeinstrom bewirkt. Dennoch hat Carbamazepin keinen Effekt auf die MEPs-Amplituden bei der kathodalen tDCS, die vermutlich eine kaliumkanalabhängige Hyperpolarisation der Membran bewirkt.

\subsubsection{Klinischer Einsatz der tDCS}

Die Anwendung der tDCS in der Klinik ist noch Gegenstand der Forschung. Denkbar wäre eine Anwendung der tDCS bei allen neuropsychiatrischen Erkrankungen, die mit pathologisch veränderter kortikaler neuronaler Aktivität vergesellschaftet sind, wie z.B. bei Schlaganfällen mit Paresen (unvollständigen Lähmungen), bei Schmerzpatienten verschiedener Schmerzarten und bei depressiven Patienten.

Die tDCS scheint eine analgetische Wirkung bei chronischen Schmerzen zu haben. Patienten mit Rückenmarksläsionen, Fibromyalgie (Fregni et al. 2006b) und Tumorschmerz (Silva et al. 2007) profitierten stark von der anodalen tDCS. 
Ein weiteres Gebiet für die Anwendung der tDCS ist die Epilepsie. In tierexperimentellen Studien hob die tDCS die epileptische Aktivität auf (Lian et al. 2003). Ähnliche Effekte erzielten Liebetanz et al. (2006). Hier erhöhte sich die Schwelle zur Auslösung epileptischer Anfälle nach kathodaler tDCS über dem sensomotorischen Kortex. Diese Steigerung der Krampfschwelle war von der Stromstärke abhängig. In einer Pilotstudie (Fregni et al. 2006a) wurde eine kathodale tDCS -1mA- über dem mutmaßlichen epileptogenen Fokus bei pharmakoresistenten Patienten mit fokaler Epilepsie bei kortikalen Malformationen über 20 Minuten verabreicht, was zu einer signifikanten Reduktion der Frequenz epileptischer Anfälle führte. Außerdem sank die Anzahl epileptischer Ereignisse in dem Monat nach kathodaler tDCS leicht, nahm allerdings nicht signifikant ab.

\subsubsection{Nebenwirkungen der tDCS}

Eine neuronale Schädigung oder ein epileptischer Anfall ist bei der tDCS denkbar. Allerdings sind bei den verwendeten Stromstärken und der Stimulationsdauer solche Nebenwirkungen nicht beobachtet worden.

Eine Studie von Poreisz et al. (2007) konnte die milden Nebenwirkungen der tDCS demonstrieren. Die Studie umfasste 567 tDCS-Sitzungen. Während der tDCS-Sitzungen wurde über ein Prickeln mit 70,6\% am meisten berichtet. 35,3\% der Probanden klagten über leichte Müdigkeit und 30,4\% berichteten über einen leichten Juckreiz unter der Stimulationselektrode. Nach den tDCS-Sitzungen gaben 11,8\% Kopfschmerzen, 2,9\% Übelkeit und 0,98\% Schlafstörungen an. Die Studie führte zu der Erkenntnis, dass die tDCS auf dem motorischen und nicht motorischen Kortex zu relativ wenigen Nebenwirkungen führt, sowohl bei Probanden als auch bei Patienten, wenn man den aktuellen Sicherheitsrichtlinien folgt.

\subsection{Transkranielle Wechselstromstimulation (tACS)}

In den letzten Jahren, wurde der Umfang der möglichen Stimulationstechniken, die die kortikale Exzitabilität beeinflussen, erarbeitet. Daraus entstand die transkranielle Wechselstromstimulation (tACS: transcranial alternating current stimulation) (Antal et al. 2008, Kanai et al. 2008, Moliadze et al. 2010, Chaieb et al. 2011) sowie noch eine speziellere Form der tACS, die transkranielle Rauschstromstimulation (tRNS: transcranial random noise stimulation) (Terney et al. 2008). Die tACS ermöglicht, im Gegensatz zur tDCS, wegen ihrer 
Eigenschaft der oszillierenden Stimulation, die äußere Interferenz mit den kortikalen Oszillationen. Diese ist bedeutend vor allem für die vorübergehende Verknüpfung kortikaler Areale, korrespondierend $\mathrm{zu}$ der sog. Bindungshypothese. Unter dem Begriff Bindungsproblem stellt man sich die neuronalen Grundlagen sensorischer Integration vor. Neuronale Oszillationen sind, zusätzlich zur Verarbeitung sensorischer Botschaften, mit Lernen, Kognition, Erregung, Aufmerksamkeit und krankhaften Zuständen (z.B. Parkinson, Tremor, Epilepsie) verknüpft (Engel et al 2001). Aus diesem Grund ist die Modifizierung von kortikalen Oszillationen ein wichtiger Baustein in der zerebralen Plastizität.

Antal et al. (2008) stimulierten mittels tACS den primären motorischen Kortex bei gesunden Probanden und leiteten dabei die MEPs nach 2 und 4 Minuten ab. Die Probanden bekamen unterschiedliche Stimulationsarten, nämlich 1, 5, 10, 15, 30, 45 Hz und Placebostimulation. Die Nacheffekte der Stimulation waren fokal und abhängig von der verwendeten Frequenz. Hieraus resultierte eine Zunahme der kortikalen Exzitabilität bei $10 \mathrm{~Hz}$ und eine Hemmung bei höheren Frequenzen. Eine Wechselstromstimulation im sog. Ripple-Frequenz-Bereich über dem primären motorischen Kortex ergibt selektive Nacheffekte (Moliadze et al. 2010). Dabei kam es zu einer Erhöhung der Exzitabilität des M1 während und nach einer Stimulation mit $140 \mathrm{~Hz}$. Keine Änderung der Exzitabilität erzielte die Placebo- und die $80 \mathrm{~Hz}-$ Stimulation. Die Ergebnisse dieser Studie weisen darauf hin, dass die tACS die neuronale Oszillation beeinflussen kann.

\subsection{Transkranielle Stimulation mit randomisiertem Strom (tRNS)}

Bei der tRNS appliziert man ein zufälliges elektrisches Frequenzspektrum (1-640 Hz) über den motorischen Kortex. Ähnliche Effekte exzitatorischer kortikaler Nacheffekte der anodalen tDCS zeigt die hochfrequente tRNS (100-640 Hz) (Terney et al. 2008). Die kortikale Exzitabilität hielt für 60-80 Minuten nach 10 Minuten tRNS-Stimulation an. Die tRNS ist eine Art Rauschen (noise). Unter Rauschen versteht man eine randomisierte, unvorhersehbare Fluktuation und Störung, die nicht zum Signal gehört, oder auch jede Störung, die mit Informationsübertragung interferiert. Rauschen ist in der Lage die Informationsverarbeitung im Gehirn auf jeder Ebene zu modifizieren. Bei sehr hohem Rauschpegel dominiert das Rauschen über die Reizantwort, während bei niedrigem Rauschpegel die Schwelle kaum überschritten wird. Die tRNS ist wahrscheinlich in der Lage mit vorhandenen Oszillationen und neuronaler Aktivitäten des Gehirns zu interferieren und so die kortikale Exzitabilität zu 
erhöhen. Die tRNS hat eine ähnliche tDCS-Wirkung, hat aber den Vorteil, unbemerkt von den Probanden appliziert zu werden (Ambrus et al. 2010).

\subsection{Motorisch evoziertes Potential (MEP)}

Ein MEP ist die elektromyographische Summenantwort eines peripheren Muskels, ausgelöst durch TMS des primären motorischen Kortex (Rothwell et al. 1999). Es resultiert aus der räumlich-zeitlichen Summation der durch die TMS ausgelösten, absteigenden Erregungssalven, die sich entlang der kortikospinalen Bahnen ausbreiten. Es wird im Interneuronen-Netzwerk des Kortex durch unterschiedliche Synapsen moduliert. In pharmakologischen Studien konnte eine Inhibition der MEP-Amplituden durch Barbiturate (GABA $A_{\mathrm{A}}$-Synergisten), Cabergolin (Dopamin-Agonist) und Guanfacin (NoradrenalinAntagonist) herbeigeführt werden, eine Vergrößerung der Amplitude konnte nach Gabe von Haloperidol (Dopamin-Antagonist), Methylphenidat (Noradrenalin-Agonist), Sertalin (Serotonin-Wiederaufnahmehemmer) und Scopolamin (Muscarin-Rezeptor-Antagonist) beobachtet werden (Ziemann 2004). Des Weiteren ist durch jede Hintergrundaktivität des Zielmuskels die Amplitude beeinflussbar. Die mittlere Amplitude mehrer MEPs gilt als elektrophysiologischer Kennwert für die kortikospinale Erregbarkeit.

\subsection{Praktische Anwendung der tDCS/tACS/tRNS}

Bei der Durchführung der tDCS/tACS/tRNS werden üblicherweise zwei Elektroden von einer Größe von $25-35 \mathrm{~cm}^{2}$ auf der Kopfhaut mit Gummibändern befestigt. Um den Kontakt zwischen den Elektroden und der Kopfhaut zu verbessern, verwendet man mit Kochsalzlösung befeuchtete synthetische Schwämme oder Elektrodencreme. Um den Widerstand so gering wie möglich zu halten, sollte man die Haut unter den Elektroden entfetten (Nitsche und Paulus 2007).

Die Elektroden werden an einen Stromstimulator angeschlossen, der eine konstante Stromstärke - meistens 1-2 mA - liefert. Zu Beginn der Stimulation spüren die Probanden bei gutem Kontakt zwischen der Kopfhaut und den Elektroden ein leichtes Kribbeln oder Jucken unter den Elektroden. Bei schlechtem Kontakt können die Untersuchten Missempfindungen aufgrund des höheren lokalen Stromflusses spüren. Um wenig bzw. keine unangenehmen Gefühle bei den Probanden hervorzurufen, wird die Stromstärke zu Beginn und am Ende der Stimulation rampenförmig erhöht bzw. rampenförmig reduziert. Je nachdem welches 
Hirnareal man stimulieren will, werden die Elektroden in einer bestimmten Reihenfolge platziert. Beim motorischen Kortex (Handareal) z.B. platziert man die eine Elektrode über den M1, die andere kontralateral über die Augenbraue. Es entsteht, je nach Einstellung z. B. ein anodaler (depolarisierender) oder ein kathodaler (hyperpolarisierender) Effekt. Für die Suche nach dem Stimulationsort (Motor hot spot) verwendet man die TMS (Nitsche und Paulus 2007).

Die tDCS/tACS/tRNS hat den Vorteil einer guten Placebostimulation. Dabei stellt man die Stromstärke bis zum Zielwert ein und lässt diese für 30-60 Sekunden laufen. Anschließend wird das Gerät abgeschaltet. So kann der Proband nicht zwischen einer Verum- und einer Placebostimulation unterscheiden und nur die Verumstimulation erzielt den gewünschten biologischen intrakraniellen Effekt (Nitsche und Paulus 2007).

\section{Ziel der Studie}

Bei Menschen ist der BDNF-Val66Met-Polymorphismus dafür bekannt, funktionelle Konsequenzen sowohl bei Patienten als auch bei gesunden Probanden zu haben, inklusive der Reduktion der Abrufkapazität in Hinsicht auf das episodische Gedächtnis (Egan et al. 2003, Pezawas et al. 2004).

Eine Studie (Cheeran et al. 2008) fand heraus, dass Met-Allel-Träger generell eine verminderte Reaktion auf die drei unterschiedlichen Stimulationsprotokolle zeigen: TBS, homeostatische Plastizität in dem tDCS/1Hz rTMS-Model (Siebner et al. 2004), gepaarte assoziative Stimulation (PAS) (Classen et al. 2004). Der Vergleich erfolgte gegenüber Trägern der Val66Val-Variante. Eine weitere Studie von Antal et al. (2010) bestätigte die Reaktionsunterschiede der $\mathrm{Val} / \mathrm{Val}$ - und Val/Met-Trägern auf drei unterschiedlichen Stimulationsprotokollen (tDCS, tRNS und iTBS).

In unserer Studie haben wir einen Follow-up unserer Ergebnisse durchgeführt, in dem eine retrospektive Genotypisierung einer großen Probandenzahl erfolgte. Die schon von unseren Laboren durchgeführten Studien forschten den Einfluss vom BDNF-Polymorphismus auf die Plastizität des M1. Die Auslösung dieser Effekte erfolgte einerseits durch anodale und kathodale tDCS, tACS und tRNS, welche modulatorische Ansätze auf die Stimulation haben, anderseits durch die iTBS, die eine Induzierung der Aktivität bewirkt. Die Daten schlagen vor, dass, abhängig vom Protokoll der spezifischen Plastizitätsinduktion, der BDNFPolymorphismus deutlich erkennbare quantitative und qualitative unterschiedliche Ergebnisse liefert. Dies legt nahe, dass es vermutlich eine Verbindung zwischen der Expression von 
bestimmten Polymorphismen im zentralen Nervensystem und den beobachteten Nacheffekten der transkraniellen elektrischen Stimulationsmethoden gibt.

\section{Material und Methoden}

\subsection{Probanden}

Aufgrund der Natur dieser retrospektiven Studie standen nicht von allen Teilnehmern, die an früheren Experimenten in unserer Abteilung teilgenommen hatten, Blutproben zur Verfügung. Einige Probanden waren nicht mehr erreichbar; andere lehnten die Teilnahme an der Genotypisierungstudie ab.

Die Gesamtzahl der Blutentnahmen und Genotypisierungen betrug 265. 136 gesunde Probanden führten Experimente durch, in denen die zeitliche Änderung der Neuroplastizität an mindestens zwei Zeitpunkten messbar war (46 Männer zwischen 18 und 45 Jahre alt). Sie nahmen an insgesamt 151 experimentellen Untersuchungen teil, sodass mehrere Probanden an mehreren Stimulationskonditionen in größeren Zeitabständen teilnahmen. Keiner der Probanden litt unter neurologischen oder psychologischen Erkrankungen. Keiner trug metallische oder elektrische Implantate. Weitere Probanden nahmen an Messungen teil, die nur zu einem Zeitpunkt durchgeführt worden sind.

115 Probanden nahmen an MEP-Messungen und 21 an kognitiven Untersuchungen teil. Bei den MEP-Messungen wurden insgesamt 130 Messungen durchgeführt. Die 136 Teilnehmer wurden wie folgt genotypisiert: 98 Teilnehmer waren homozygot für den Val-Allel (Val66Val) und 38 Teilnehmern waren heterozygot für den Val66Met-Allel.

Die Folgende Tabelle gibt eine Übersicht über das Probandenkollektiv:

\begin{tabular}{|c|c|c|c|c|c|c|}
\hline Stimulation & a-tDCS & & k-tDCS & & tACS & \\
\hline Genotyp & $19 \mathrm{Val} / \mathrm{Val}$ & 13Val/Met & 11Val/Val & 8Val/Met & 7Val/Val & 6Val/Met \\
\hline Probanden & $11 \mathrm{~W} / 8 \mathrm{M}$ & $8 \mathrm{~W} / 5 \mathrm{M}$ & $5 \mathrm{~W} / 6 \mathrm{M}$ & $4 \mathrm{~W} / 4 \mathrm{M}$ & $5 \mathrm{~W} / 2 \mathrm{M}$ & $1 \mathrm{~W} / 5 \mathrm{M}$ \\
\hline Stimulation & tRNS & & iTBS & & & \\
\hline Genotyp & 30Val/Val & 13Val/Met & 15Val/Val & 8Val/Met & & \\
\hline Probanden & 19W/11M & $10 \mathrm{~W} / 3 \mathrm{M}$ & $10 \mathrm{~W} / 5 \mathrm{M}$ & $6 \mathrm{~W} / 2 \mathrm{M}$ & & \\
\hline
\end{tabular}




\subsection{Vorbereitung vor den MEP-Messungen}

Die Probanden saßen während der Messungen in einem bequemen Zahnarztsessel mit verstellbarer Lehne und verstellbarer Kopfstütze in halbsitzender Position. An der rechten Hand wurden 2 Ag/AgCl-Oberflächenelektroden (Durchmesser 9mm) zur Ableitung der Muskelsummenaktionspotentiale (MSAP) mittels Elektromyogramm (EMG) angebracht; das Rohsignal wurde amplifiziert und mit einem Tiefenpassfilter (2 kHz) gefiltert. Das Signal wurde im Anschluss über einen micro 1401 analog-zu-digital Wandler (Cambridge Electronic Design, Cambridge, UK) mit einer Wechselrate von $5 \mathrm{kHz}$ digitalisiert und unter Kontrolle

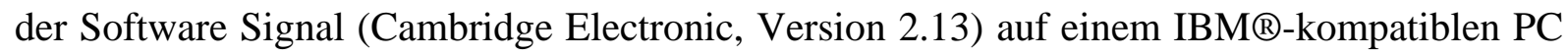
zur genaueren Bewertung gespeichert.

\subsection{BDNF- Genotypisierung}

Die BDNF-Genotypisierung fand im Institut für Genetik der Universität Göttingen statt. Es wurde Vollblut in EDTA-Röhrchen abgenommen und die DNA wurde mittels Standardmethoden extrahiert. Die Konditionen der Primer-Sequenzen und der PCR sind auf Anfrage erhältlich. Der Erfolg der PCR wurde auf Agarose/2 x TBE-Gelplatte geprüft. Die Analyse des Restriction Fragment Length Polymorphism (RFLP) erfolgte mit dem Restriktionsenzym Hsp92II. Die Restriktionsprodukte wurden mittels Elektrophorese auf einem 2\%Agarose-Gel mit einem Transilluminator und Ethidiumbromid-Färbung dargestellt. Nach Verdauung ergab der Val-Allel (G) zwei Fragmente: 57 und 217 bp, während der MetAllel (A) drei Fragmente ergab: 57, 77 und 140 bp.

\subsection{Elektrische und magnetische Stimulation: tRNS, tACS, tDCS und iTBS}

Die elektrische Stimulation wurde mittels eines batteriegesteuerten Stimulators (DCStimulator-Plus, NeuroConn GmbH, Ilmenau, Deutschland) appliziert. Die Stromstimulation wurde durch Gummielektroden, die in zwei Schwämmen platziert waren, geliefert. Mittels TMS wurde vor Stimulationsbeginn der linke M1 ausfindig gemacht. Über diesem Areal wurde die Stimulationselektrode und über der rechten Augenbraue die Referenzelektrode platziert und mit Gummibändern befestigt.

tRNS: 43 Probanden nahmen an dieser Studie teil, hiervon 30 homozygote. Die Größe der Stimulationselektrode betrug $4 \times 4 \mathrm{~cm}$, die der Referenzelektrode $6 \times 14 \mathrm{~cm}$. Die tRNS wurde für 
10 Minuten appliziert. Der Stimulator generierte im Programm „noise“ ein normalverteiltes Weißes Rauschen (Abtastrate 1280 sps). Das Signal ist normal verteilt, da alle Frequenzen bis zur Hälfte der möglichen Wechselrate $(640 \mathrm{~Hz})$ zu gleichen Teilen im Signal enthalten sind. Der Begriff Weißes Rauschen bezieht sich auf die spektrale Leistungsdichte des erzeugten Wechselstromes. Die Rauschwerte sind voneinander unabhängig und folgen bei der Beobachtung über einem längeren Zeitintervall idealerweise einer Gauß’schen-Glockenkurve. Des Weiteren ist der applizierte Strom bipolar und mittelwertfrei. Die hierbei verwendete Stromstärke von $1000 \mu \mathrm{A}$ besagt, dass 99\% aller abgegebenen Strompegel zwischen +500 $\mu \mathrm{A}$ und $-500 \mu \mathrm{A}$ liegen. Nur 1\% der Strompegel waren größer als $\pm 500 \mu \mathrm{A}$ und die maximal aufgetretenen Stromstärken lagen bei $\pm 600 \mu \mathrm{A}$.

tDCS: 51 Probanden nahmen an dieser Studie teil. 32 anodale Stimulationen, hiervon 13 heterozygote, und 19 kathodale Stimulationen, hiervon 8 heterozygote, wurden durchgeführt. Hier betrug die Elektrodengröße 5x7 cm. Die anodale Stimulation wurde 7-10 Minuten, die kathodale 10-13 Minuten appliziert (Nitsche und Paulus 2000, 2001, Nitsche et al. 2003). Der Gleichstrom floss kontinuierlich mit einer Stromstärke von $1 \mathrm{~mA}$. Zur Vermeidung von Phosphenen wird die Stromstärke zu Beginn und am Ende der tDCS rampenförmig erhöht bzw. rampenförmig reduziert.

tACS: 13 Probanden nahmen an dieser Studie teil. Davon waren 7 Probanden Träger des Val/Val-Allels, die restlichen 6 waren Val/Met-Träger. Die Größe der Stimulationselektrode betrug 4x4cm, die der Referenzelektrode 6x14cm. Die tACS (140 Hz) wurde für 10 Minuten appliziert.

iTBS: 23 Probanden nahmen an dieser Studie teil (8 heterozygote). Die Applikation der iTBS erfolgte mittels Magstim Super Rapid (Magstim Company, Whiteland, Wales, UK) mit einer Standard Achterspule (figure-of-eight-coil) und einem MagPro-Stimulator (Medtronic, Denmark). Die Spulen hatten einen äußern Radius von 70 und 75 mm und einem posterioranterior-posterior-Flow. Die Stimulationsintensität betrug $80 \%$ der aktiven motorischen Schwelle (AMT). Die AMT's wurden definiert als die niedrigste Stimulationsintensität, bei der 3 von 6 konsekutive Stimuli zuverlässige MEPs (von 200 $\mu$ V Amplitude) des rechten ersten Musculus Interosseus dorsalis (FDI) oder des Musculus abductor digiti minimi (ADM) hervorrufen (Rothwell et al. 1999). Das Muster der rTMS besteht aus bursts. Diese enthalten 3 Pulse mit einer Frequenz von $50 \mathrm{~Hz}$ und einem Wiederholungsintervall von 200 ms (d.h. mit $5 \mathrm{~Hz}$ ). Eine TBS-Stimulationsfolge von 2 Sekunden wurde jede 10 Sekunden für insgesamt 190 Sekunden (600 Pulse) (Huang et al. 2005) appliziert. Die Lokalisation der 
Spule wurde bei jedem Probanden individuell bestimmt. Zuerst wurde der linke M1 aufgesucht. Die Spule hatte eine tangentiale Position zur Schädelkalotte, der Spulengriff zeigte nach posterolateral in ca. einem Winkel von $45^{\circ}$ zur Sagittalebene.

\subsection{TMS-Messung}

Für die experimentellen Untersuchungen wurden monophasische Magnetimpulse mittels eines Magstim 200 Magnetstimulators generiert (Magstim Company, Whiteland, Wales, UK). An den Stimulator wurde eine achtförmige Magstim-Double-70-mm-Spule (Durchmesser der Spulenwindungen $\sim 70 \mathrm{~mm}$ ) angeschlossen. Damit konnte man eine maximale Feldstärke von 2,2 Tesla mit einer mittleren Selbstinduktion von 16,35 $\mu \mathrm{H}$ erreichen.

Um die induzierte Exzitabilitätsänderung zu erfassen, wurden die MEPs des ADM oder des FDI aufgezeichnet. Die Aufzeichnung erfolgte bei Stimulation der kortikalen Repräsentationsareale der beiden Muskeln mittels sTMS. Zur Stimulation wurde ein Magstim 200 oder einen MagPro Stimulator mit einer Achterspule (Durchmesser der Windung 70 und $75 \mathrm{~mm}$ ) benutzt. Während der Untersuchungen hatte die Spule eine tangentiale Position zur Schädelkalotte, der Spulengriff zeigte nach posterolateral in ca. einem Winkel von $45^{\circ}$ zur Sagittalebene. Um die bestgeeignete Stelle zu finden, wurde die Spule unter der Generierung von Einzel-Puls-Testreizen in kleinen Stufen über den primären motorischen Kortex der linken Hemisphäre hin und her bewegt. Bei zu niedriger bzw. abwesender EMG-Aktivität, wurde schrittweise die Intensität der Testreize erhöht und erneut die optimale Spulenposition aufgesucht. Bei einer optimalen Positionierung erhielt man große und stabile MEPAmplituden. Diese Stelle, auch hot-spot genannt, wurde farblich markiert.

Nach der Bestimmung der Schwellenwerte folgte die Messung der Baseline. Die Intensität der Einzelpulse wurde so gewählt, dass die erzeugten MEP-Amplituden einen Peak-to-Peak Wert von ca. $1 \mathrm{mV}$ erzeugten. Der so entstandene Mittelwert aus den MEP-Amplituden sollte womöglich bei $1 \mathrm{mV}$ liegen. Die Baseline und die folgenden Messblöcke enthalten 20-40 Einzelpulsstimuli mit einer Frequenz von 0,25 Hz. 


\subsection{Kognitive Untersuchung}

$\underline{\text { Nachweis der Beeinflussbarkeit der kognitiven Leistung bezüglich konzeptualen Lernens }}$ durch tDCS/tACS durch die Modulation des DLPFC:

Für diese Untersuchung haben wir die Feedback-unterstützte, visuelle Konzeptlern-Aufgabe gewählt (Seger et al. 2000). Dieser Test ermöglicht uns nicht nur die Kategorisierungsleistung in den etablierten Kategorien nach der Erstausbildung zu messen, sondern auch die Auswirkungen der Stimulation während der Lernphase zu beobachten. Seger et al. (2000) untersuchten die Hirnaktivität in der Akquisitionsphase. Die Autoren haben eine erhöhte Aktivität im rechten DLPFC und im rechten inferioren parietalen Bereich gefunden. Nach Ansicht der Autoren könnte dieses Phänomen darauf hindeuten, dass die Aktivierung der rechten Gehirnhälfte in diesem Fall das Kategorielernen reflektiert.

\section{$\underline{\text { Messprotokoll }}$}

In der Studie der kognitiven Untersuchung nahmen 21 Probanden teil. Davon waren es 10 Männer und 11 Frauen. Von den 21 Probanden waren es 5 Träger des Val66Met-Allels. Es erfolgte eine anodale Stimulation der rechten DLPFC.

Wir benutzten die Stimuli und das Protokoll von Seger et al. (2000). Jeder Stimulus $(10 \times 10$ Gitter) ist mit roten und blauen Quadraten ausgefüllt. Niedrige und hohe Verzerrungsstimuli werden durch die zufällige Inversion von 10 und 20\% des Prototyp-Musters produziert. Während der Akquisitionsphase sahen die Probanden nur die niedrigen und hohen Verzerrungsstimuli, während bei dem Test und dem Retest die geringen Verzerrungen, hohen Verzerrungen und Prototyp-Muster vorgestellt wurden.

Vor Beginn der Trainingsphase wurde den Probanden gesagt, dass sie Bilder von zwei abstrakten Künstlern, Smith und Jones, in Kategorien einteilen müssen. Sie wurden darüber informiert, dass sie während des Trainings ein kontinuierliches Feedback über ihre Leistung erhalten werden. Die Trainingsphase enthält zehn Blöcke. In jedem Block werden die 10 geringen Verzerrungs- (5 vom Prototyp A, 5 vom Prototyp B abgeleitet) und die 10 hohen Verzerrungsstimuli (5 vom Prototyp A, 5 vom Prototyp B) jeweils für 2500 ms präsentiert. Der Proband muss die vorgestellten Muster kategorisieren, indem er entweder die linke oder die rechte Pfeiltaste auf der Tastatur drückt. Die Zeit ist unbegrenzt. Unmittelbar nach der Entscheidung bekommt der Proband eine Rückmeldung darüber, ob die Entscheidung richtig oder falsch war. Diese Nachricht wird auf dem Bildschirm für 500 ms präsentiert. Die Testphase hat vier Blöcke. Zehn niedrige und zehn starke Verzerrung-Muster und die beiden Prototypen (A und B) werden in jedem Block präsentiert. Die Probanden müssen die gleichen 
Kategorieurteile wie in der Trainingsphase machen, diesmal aber ohne Rückmeldung. Die Aufgabe in der Retest-Phase war mit der Testphase in jeder Hinsicht identisch. Nach der morgendlichen Retest-Phase wurden die Teilnehmer gebeten, ein typisches Muster von beiden "abstrakten Malern" zu produzieren. Sie bekamen zwei leere $10 \times 10$ Gitter und konnten beide Muster gleichzeitig mit der Computermaus bearbeiten. Diese Reproduktionen wurden mit einem automatisierten computerbasierten Algorithmus analysiert (Empfindlichkeit Index: Reproduktion Genauigkeit).

\subsection{Experimentaler Aufbau}

Während der Stimulation saßen die Probanden auf einem bequemen Liegestuhl mit Kopfstütze. Die Stimulation innerhalb einer Gruppe wurde immer von demselben Untersucher durchgeführt.

\subsection{Datenauswertung}

MEPs: Begonnen wurde mit einer deskriptiven Auswertung der erzeugten MEPs. Die durch die Software-Signale dargestellten Kurven wurden mit dem Programm NuCursor weiter analysiert. In einem vom Untersucher vorgegebenen Intervall wurde die Differenz zwischen den Werten des oberen und des unteren Umschlagpunktes (Peak-to-Peak-Amplitude) errechnet. Pro Messung entstanden so je 20-40 Werte, aus denen separat für jede Messung das arithmetische Mittel und die Standardabweichung bestimmt wurden (für die Baseline und neun Nachmessungen). Im gleichen Arbeitsschritt konnten auch artifizielle Werte entfernt werden, die unter anderem durch willkürliche Bewegungen des Probanden entstanden waren. Die errechneten MEP-Mittelwerte der Nachmessungen wurden gegenüber der Baseline standardisiert.

Kognitive Aufgabe: Bei der Analyse der kognitiven Aufgaben wurde die Leistung der Probanden in zwei Phasen verglichen. Es erfolgte eine deskriptive Auswertung der Test- und Retest-Phase. Ebenso wurden die Reaktionszeiten in den beiden Phasen berechnet.

\subsection{Statistische Auswertung}

Die statistische Auswertung erfolgte mit dem Programm Statistica ${ }^{\circledR}$ (StatSoft Europe GmbH, Hamburg, Deutschland). Dazu wurden mehrere Varianzanalysen für Untersuchungen mit Messwiederholungen (ANOVAs) durchgeführt. Zuerst untersuchten wir die Effektivität des 
Genotyps. Dazu verwendeten wir eine ANOVA mit einem Faktor „Genotyp“ (Val/Val vs. Val/Met) und „Messzeitpunkt“ (3 Ebenen: 0, 30 und $60 \mathrm{~min}$ ). Danach verglichen wir die unterschiedlichen Stimulationsarten in den einzelnen Genotyp-Gruppen. Wenn sich ein Haupteffekt für den Faktor „Genotyp“ oder „Stimulation“ oder „Messzeitpunkt“ oder eine Interaktion zwischen „Genotyp“ / „Stimulation“ und „Messzeitpunkt“ zeigte, wurde ein Tukey Test durchgeführt. Ein $p$-Wert von $<.05$ wurde als signifikant für alle statistischen Untersuchungen gewertet.

Zum Vergleich der nicht-normalisierten MEP-Amplituden der einzelnen Nachmessungen zu der jeweiligen Baseline vor Stimulation wurde ein Student’s t-test durchgeführt.

Die Auswertung der kognitiven Aufgaben wurde aufgrund der niedrigen Zahl der Val-MetProbanden nur deskriptiv durchgeführt. Der Verlauf der kognitiven Leistung über die 10 Blöcke wurde zwischen den beiden Gruppen verglichen. Der Vergleich erfolgte sowohl in der Test- als auch in der Retest-Phase. Weiterhin wurde die Reaktionszeit der Probanden während der Aufgaben ermittelt. 


\section{Ergebnisse}

\section{Kathodale tDCS}

Die kathodale Stimulation hemmte die kortikale Exzitabilität in beiden Probandengruppen (siehe Abbildung 1).

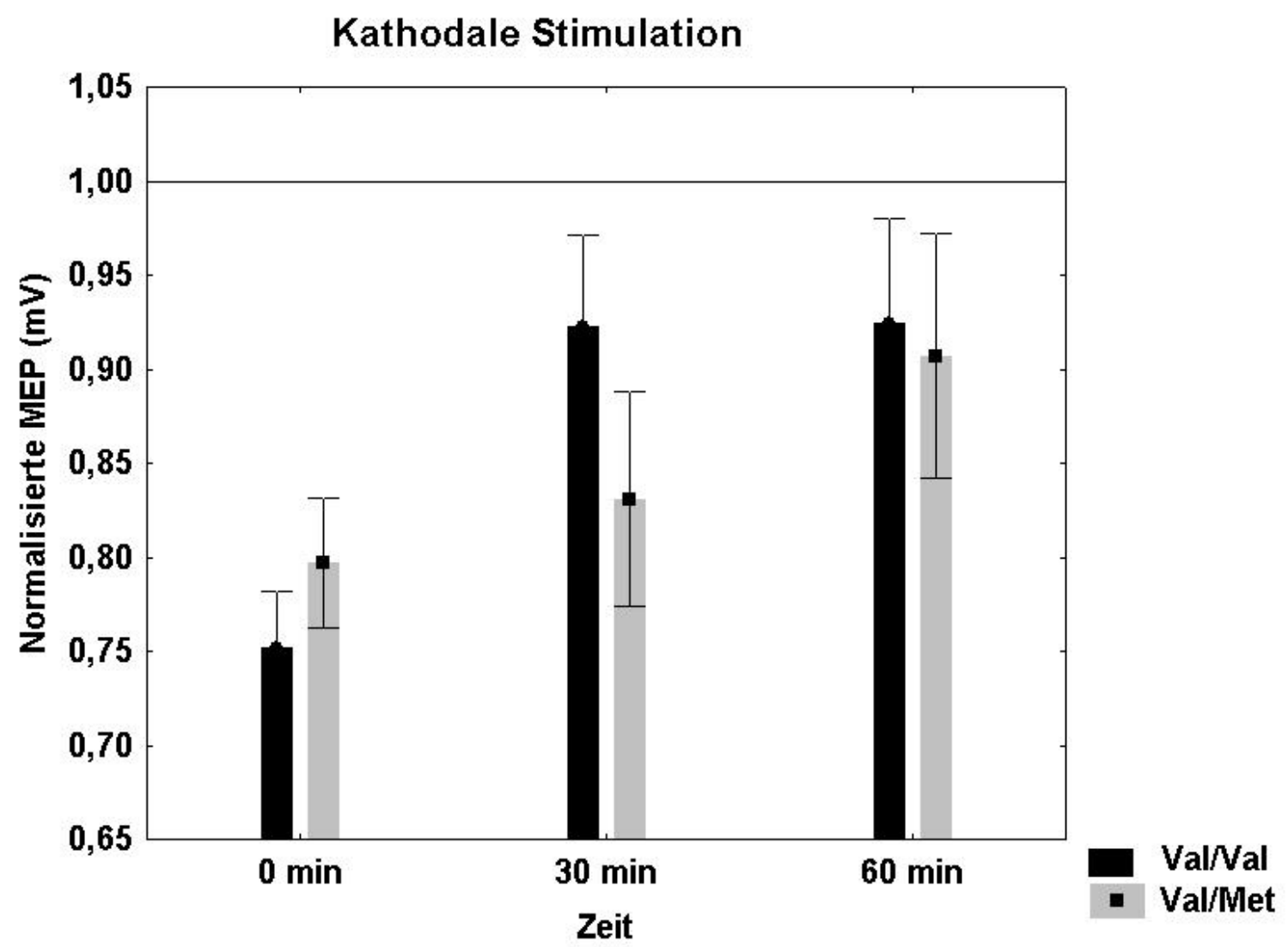

Abbildung 1: Effekt des BDNF Val66Met-Polymorphismus auf die kortikale Exzitabilität bei Anwendung kathodaler tDCS

Durch ANOVAs mit Messwiederholungen konnte kein signifikanter Haupteffekt der kathodalen tDCS für „Genotyp“, $F_{1,17}=0.199, p=0.66$, nachgewiesen werden. Der Faktor „Messzeitpunkt“ war signifikant, $F_{2,34}=5.34, p=0.009$. Es zeigte sich keine signifikante Interaktion zwischen „Genotyp“ und „Messzeitpunkt“, F2,34 = 1.63, $p=0.32$. Die Analyse mit dem Student's t-test zeigte eine signifikante Hemmung der MEP-Amplituden nach kathodaler tDCS zu den Zeitpunkten 0 min und 60 min $(p<.05)(V a l / V a l$ Gruppe) und zu den Zeitpunkten 0 min und 30 min $(p<.05)$ (Val/Met Gruppe) verglichen mit der Baseline. 


\section{Anodale tDCS}

Die anodale Stimulation erhöhte die kortikale Exzitabilität in beiden Gruppen (siehe Abbildung 2).

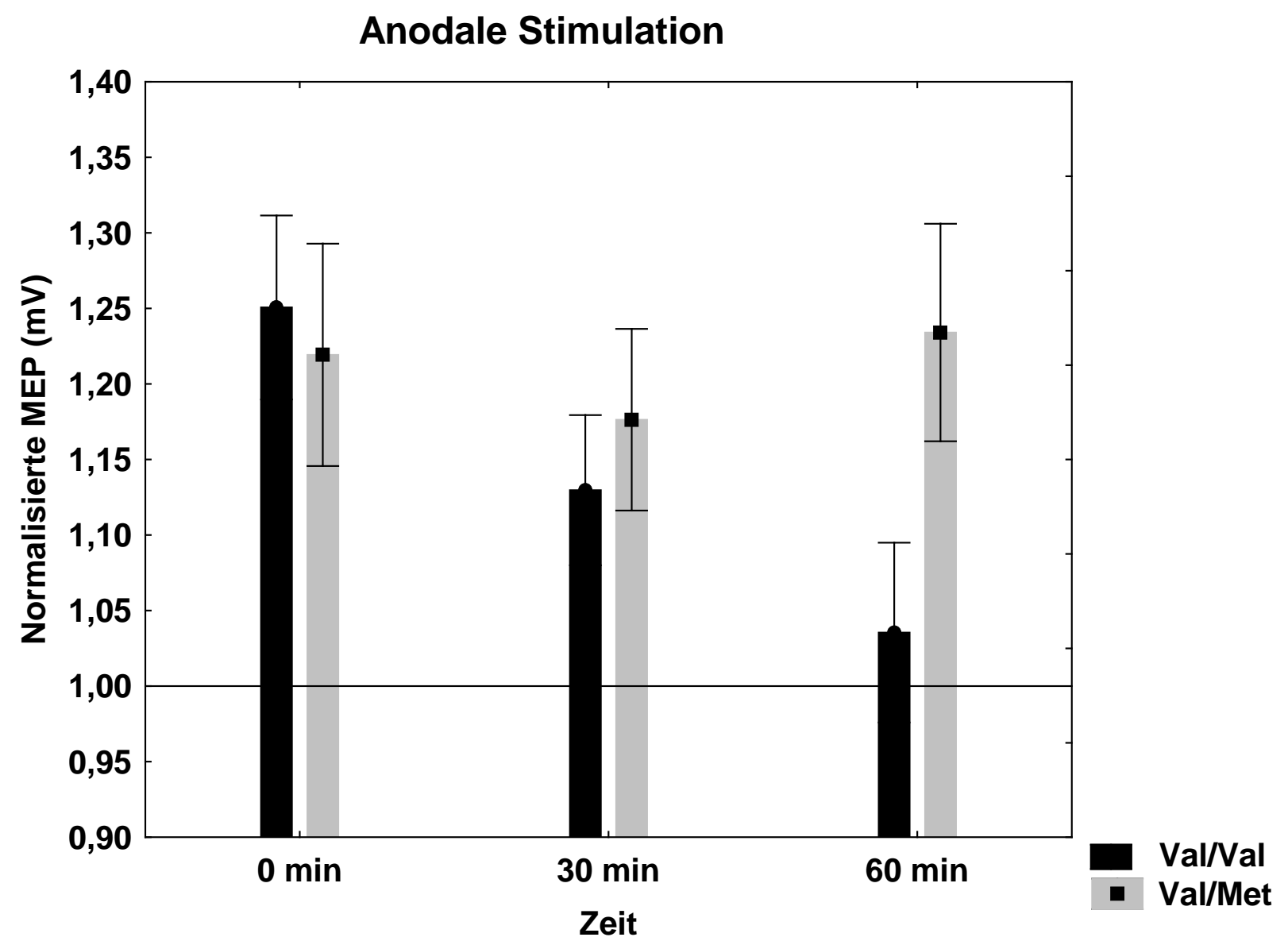

Abbildung 2: Effekt des BDNF Val66Met-Polymorphismus auf die kortikale Exzitabilität bei Anwendung anodaler tDCS

Durch ANOVAs mit Messwiederholungen konnte kein signifikanter Haupteffekt der anodalen tDCS für „Genotyp“, $F_{1,30}=2.51, p=0.12$, nachgewiesen werden. Der Faktor „Messzeitpunkt“ war nicht signifikant, $F_{2,60}=1.28, p=0.29$. Es zeigte sich ebenfalls keine signifikante Interaktion zwischen „Genotyp“ und „Messzeitpunkt“, $F_{2,60}=1.53, p=0.22$. Die Analyse mit dem Student's t-test zeigte eine signifikante Erhöhung der MEP-Amplituden nach tDCS zu den Zeitpunkten 0 min und 30 min $(p<.05)$ (Val/Val Gruppe) und zu den Zeitpunkten $0 \mathrm{~min}, 30 \mathrm{~min}$ und $60 \mathrm{~min}(p<.05)$ (Val/Met Gruppe) verglichen mit der Baseline. 


\section{tRNS}

Die tRN Stimulation erhöhte die kortikale Exzitabilität in beiden Gruppen (siehe Abbildung 3).

\section{tRN Stimulation}

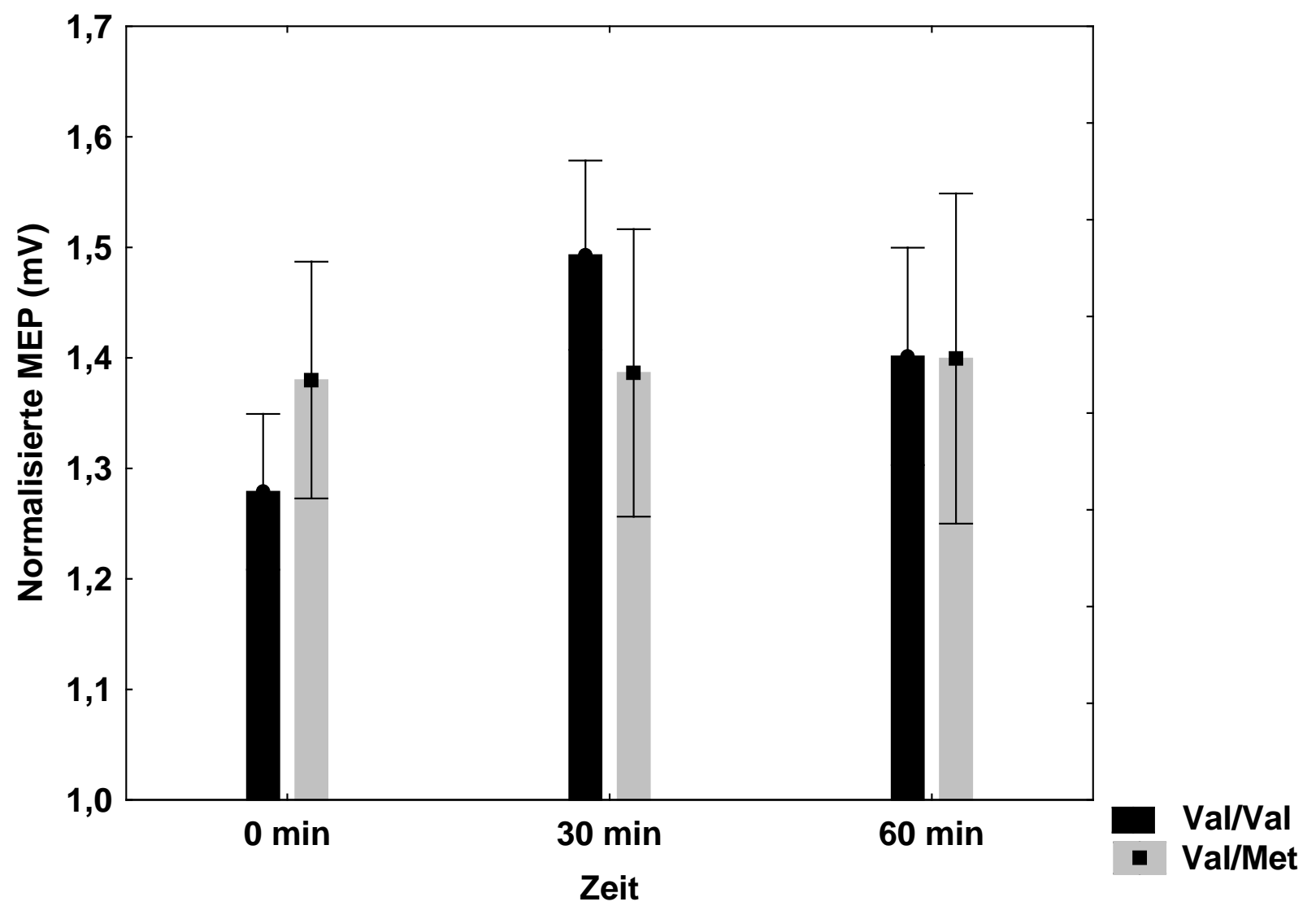

Abbildung 3: Effekt des BDNF Val66Met-Polymorphismus auf die kortikale Exzitabilität bei Anwendung der tRNS

Durch ANOVAs mit Messwiederholungen konnte kein signifikanter Haupteffekt der tRNS für „Genotyp“, $F_{1,41}=0.0004, p=0.98$, nachgewiesen werden. Der Faktor „Messzeitpunkt“ war nicht signifikant, $F_{2,82}=0.88, p=0.42$. Es zeigte sich keine signifikante Interaktion zwischen „Genotyp“ und „Messzeitpunkt“, $F_{2,82}=0.75, p=0.47$. Die Analyse mit dem Student's t-test zeigte eine signifikante Erhöhung der MEP-Amplituden nach tRNS zu den Zeitpunkten 0 min, 30 min und $60 \mathrm{~min}(p<.05)(\mathrm{Val} / \mathrm{Val}$ und Val/Met Gruppen) verglichen mit der Baseline. 


\section{tACS}

Die tACS Stimulation erhöhte die kortikale Exzitabilität in beiden Gruppen (Abbildung 4). Durch ANOVAs mit Messwiederholungen konnte kein signifikanter Haupteffekt der tACS für „Genotyp“, $F_{1,11}=0.16, p=0.69$, nachgewiesen werden. Der Faktor „Messzeitpunkt“ war nicht signifikant, $F_{2,22}=0.031, p=0.97$. Es zeigte sich keine signifikante Interaktion zwischen „Genotyp“ und „Messzeitpunkt“, $F_{2,22}=2.01, p=0.16$. Die Analyse mit dem Student's t-test zeigte eine signifikante Erhöhung der MEP-Amplituden nach tACS zum Zeitpunkt 30 min $(p<.05)($ Val/Val Gruppe) verglichen mit der Baseline.

\section{tAC Stimulation}

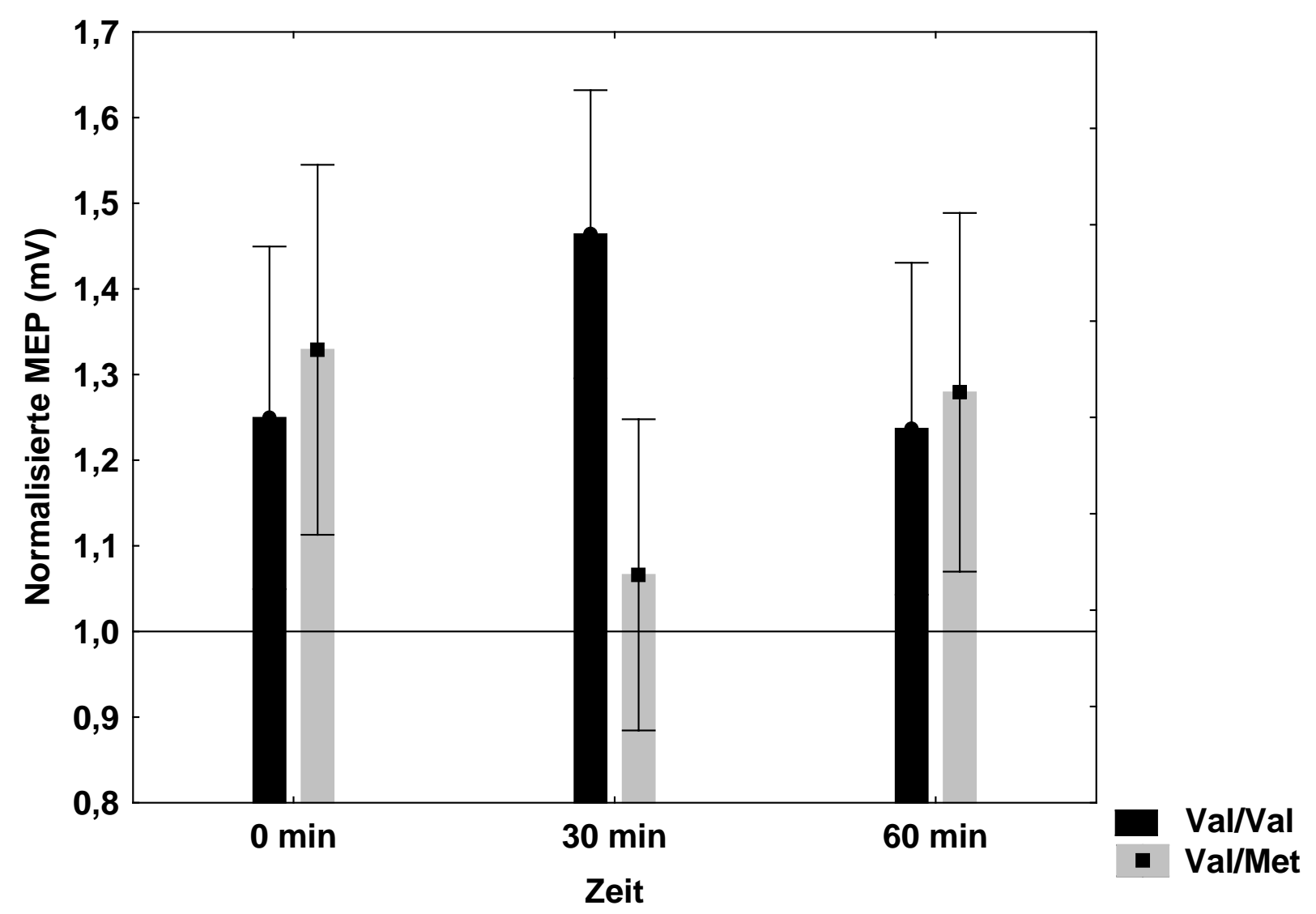

Abbildung 4: Effekt des BDNF Val66Met-Polymorphismus auf die kortikale Exzitabilität bei Anwendung der tACS 


\section{iTBS}

Die iTBS erhöhte die kortikale Exzitabilität nur in der Val/Val Gruppe (Abbildung 5). Durch ANOVAs mit Messwiederholungen konnte kein signifikanter Haupteffekt der iTBS für „Genotyp“, $F_{1,21}=2.5, p=0.13$, nachgewiesen werden. Der Faktor „Messzeitpunkt“ war signifikant, $F_{2,42}=4.5, p=0.02$. Es zeigte sich keine signifikante Interaktion zwischen „Genotyp“ und „Messzeitpunkt“, $F_{2,42}=0.08, p=0.92$. Die Analyse mit dem Student’s $t$-test zeigte eine signifikante Fazilitation der MEP-Amplituden nach iTBS zu den Zeitpunkten 0 min und $60 \min (p<.05)(V a l / V a l$ Gruppe) verglichen mit der Baseline.

\section{Theta-burst Stimulation}

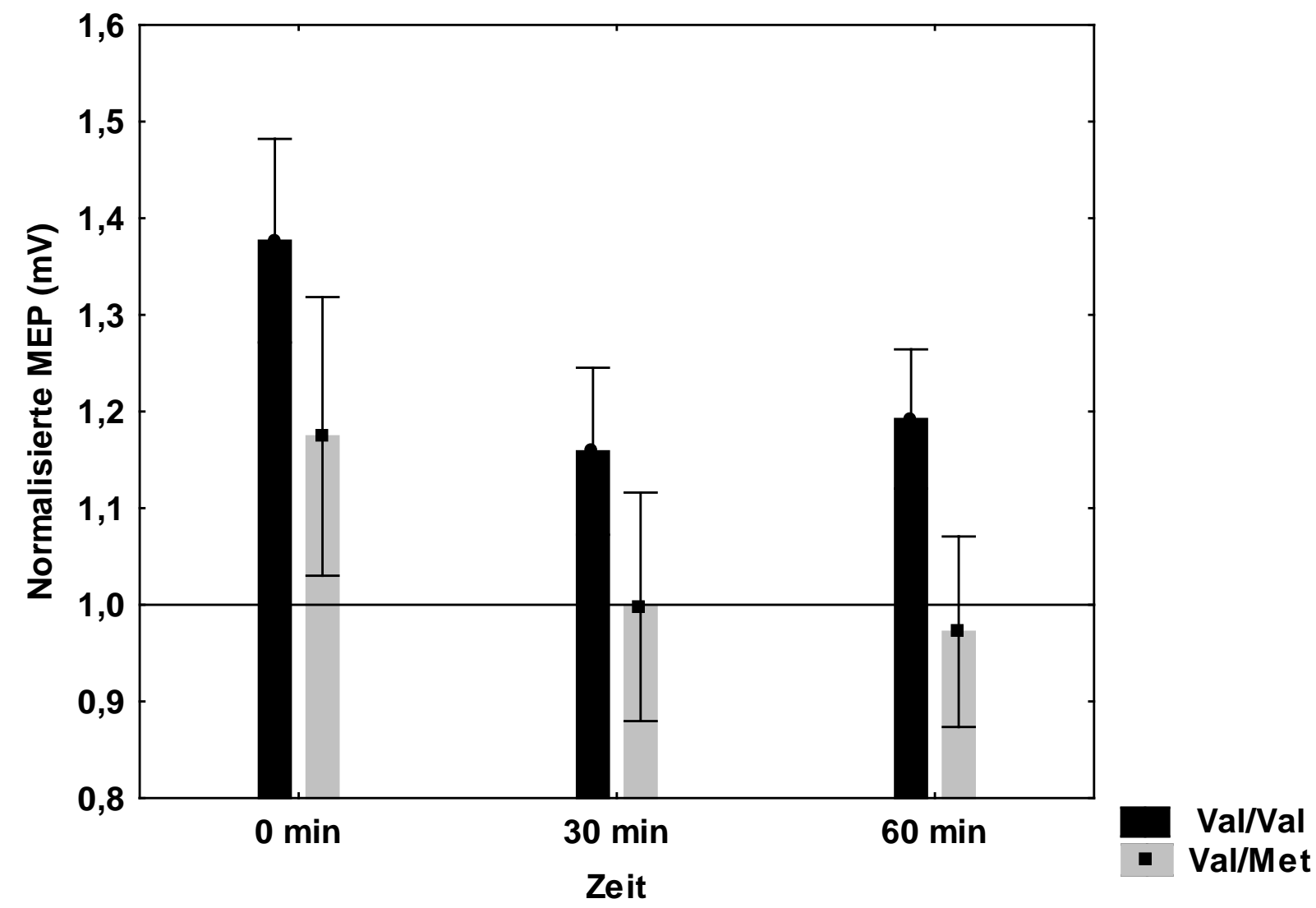

Abbildung 5: Effekt des BDNF Val66Met-Polymorphismus auf die kortikale Exzitabilität bei Anwendung der iTBS 


\section{Vergleich der Stimulationsarten untereinander}

Alle exzitatorischen Stimulationsarten, gleichzeitig verglichen in der Val/Val Gruppe, ergaben einen signifikanten Effekt von Stimulation $F_{3,67}=2.69, p=.05$. Der „Messzeitpunkt“ war nicht signifikant, $F_{2,134}=1.33, p=0.26$. Die Interaktion zwischen „Stimulation“ und „Messzeitpunkt“ war signifikant, $F_{6,134}=2.56, p=0.02$. Die anschließenden post-hocAnalysen zeigten, dass die Amplituden der anodalen tDCS signifikant kleiner waren im Vergleich zu tRNS und tACS, $p<.05$, um 30 Minuten.

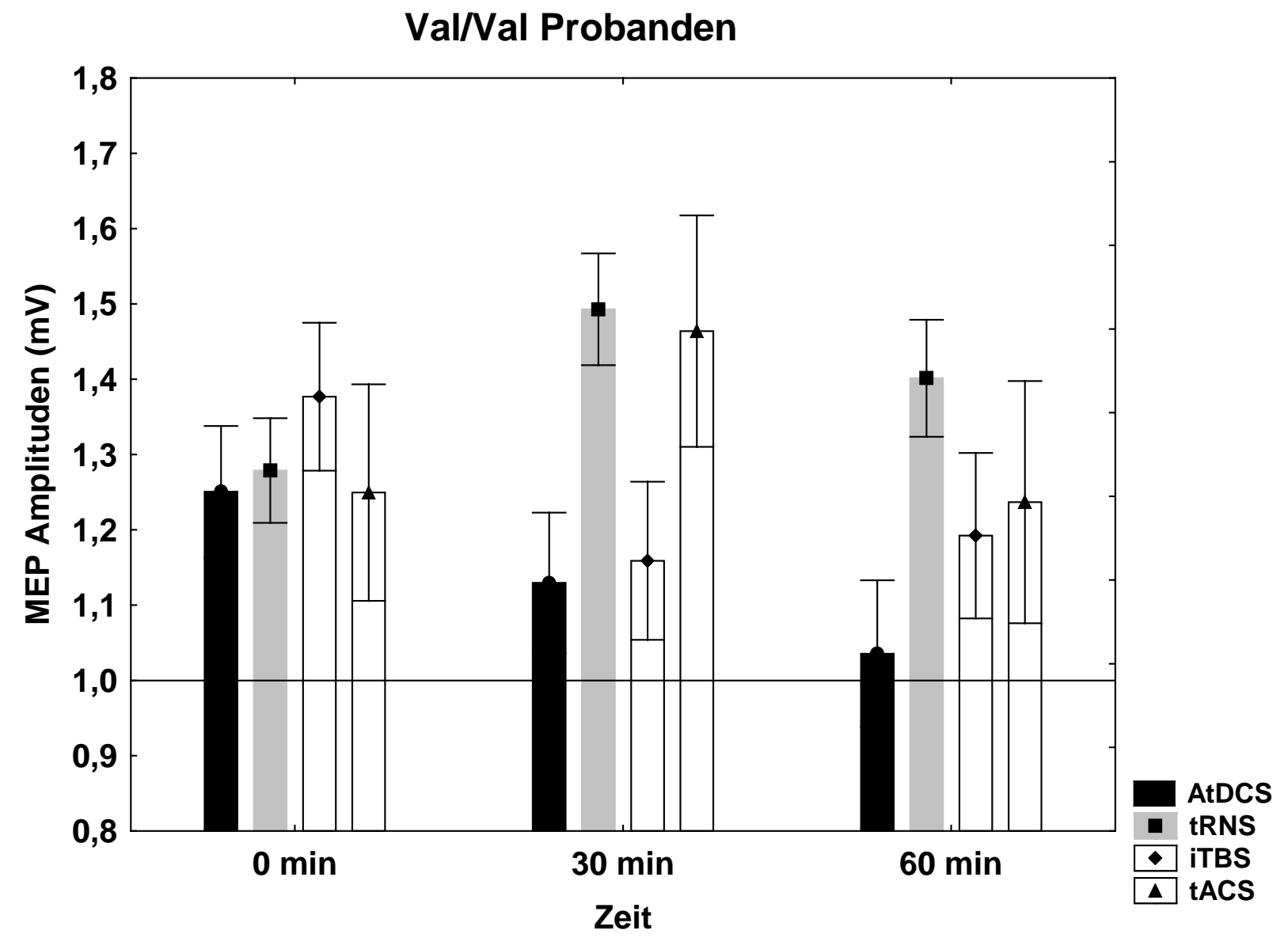

Abbildung 6: Vergleich der Stimulationsverfahren untereinander bei Val/Val-Probanden

Alle exzitatorische Stimulationsarten gleichzeitig verglichen in der Val/Met Gruppe ergaben keinen Effekt von Stimulation $F_{3,36}=2.35, p=0.087$. Der Faktor „Messzeitpunkt“ war nicht signifikant, $F_{2.72}=1.47, p=0.24$. Die Interaktion zwischen „Stimulation“ und „Messzeitpunkt““ war nicht signifikant, $F_{6.72}=0.58, p=0.74$. 


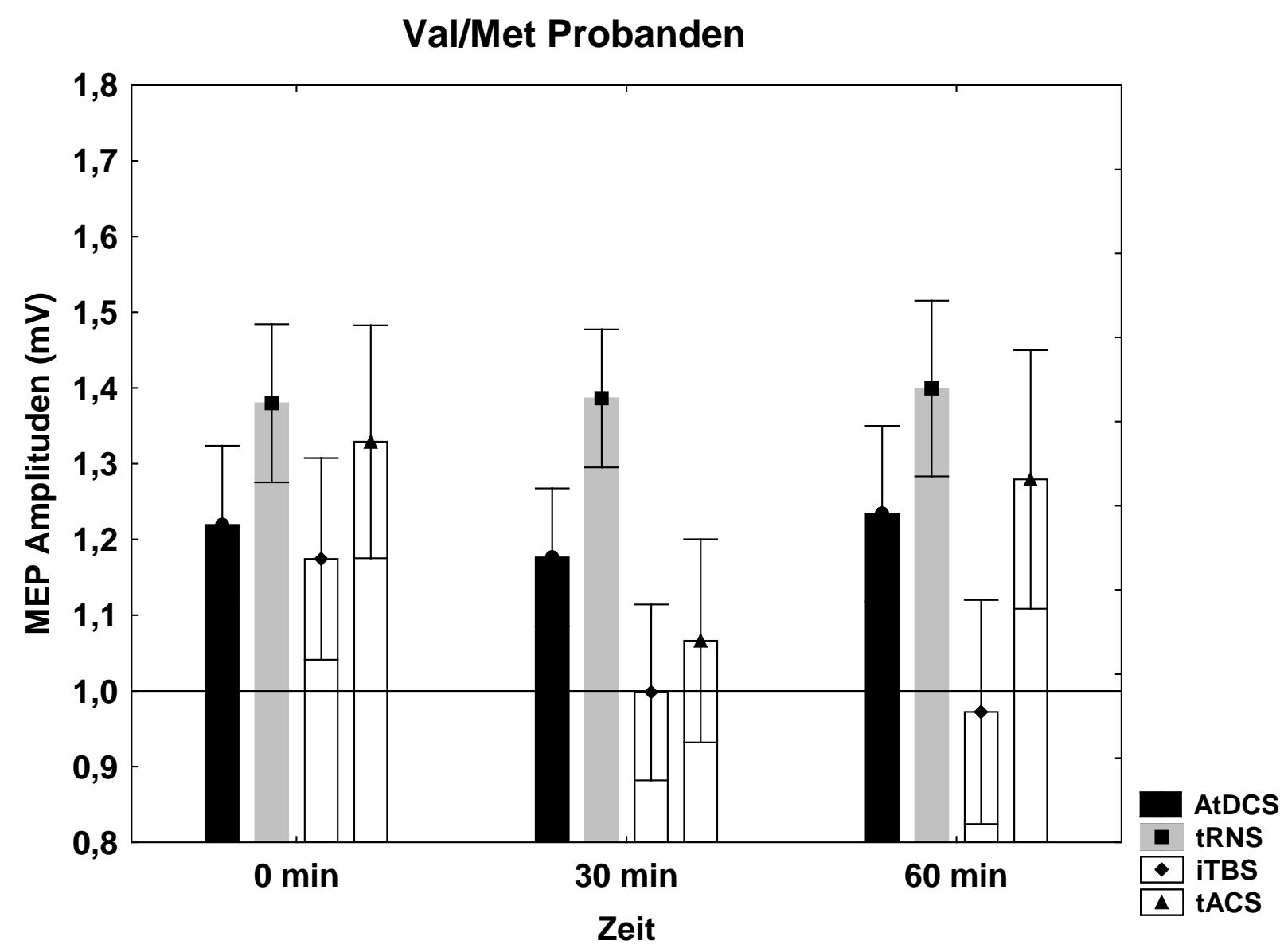

Abbildung 7: Vergleich der Stimulationsverfahren untereinander bei Val/Met-Probanden

\section{Analyse der kognitiven Tests}

Hier erfolgte nur eine deskriptive Statistik wegen der geringeren Zahl der Val/MetProbanden. Die kognitive Leistung der Val/Met-Probanden war deutlich niedriger in der Testund Retest-Phase als die der Val/Val-Probanden. In den Reaktionszeiten der Retest-Phase haben die Val/Val-Probanden besser abgeschnitten als die Val/Met-Probanden. Der Unterschied war dabei nicht ausgeprägt. Dagegen gab es keinen Unterschied in den Reaktionszeiten der Test-Phase in den beiden Gruppen. 

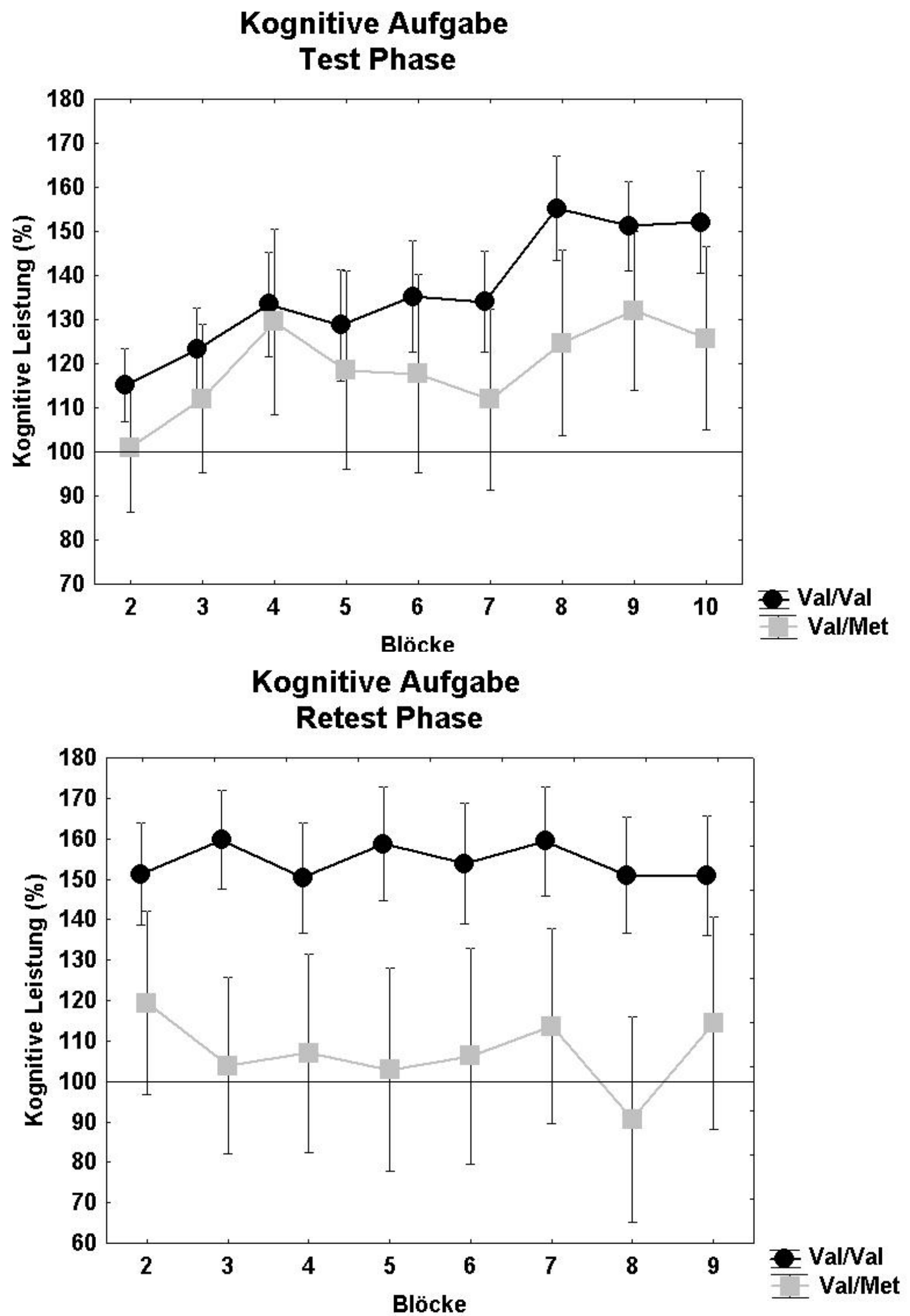

Abbildung 8: Vergleich der kognitiven Leistung zwischen Val- und Met-Allel-Trägern in der Testphase (oben) und der Retestphase (unten) 


\section{Kognitive Aufgabe - Reaktionzeit \\ Test Phase}

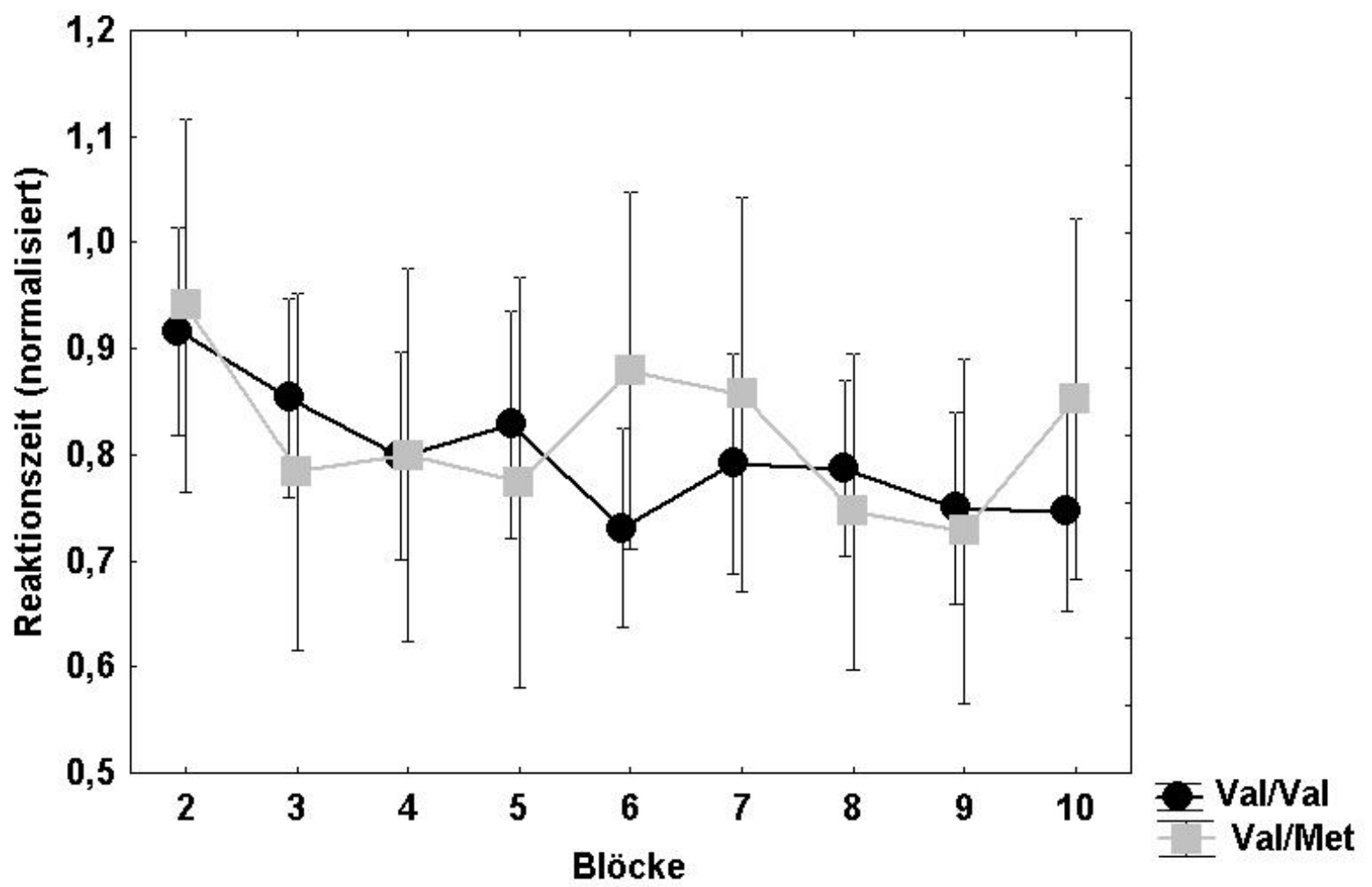

Kognitive Aufgabe - Reaktionzeit Retest Phase

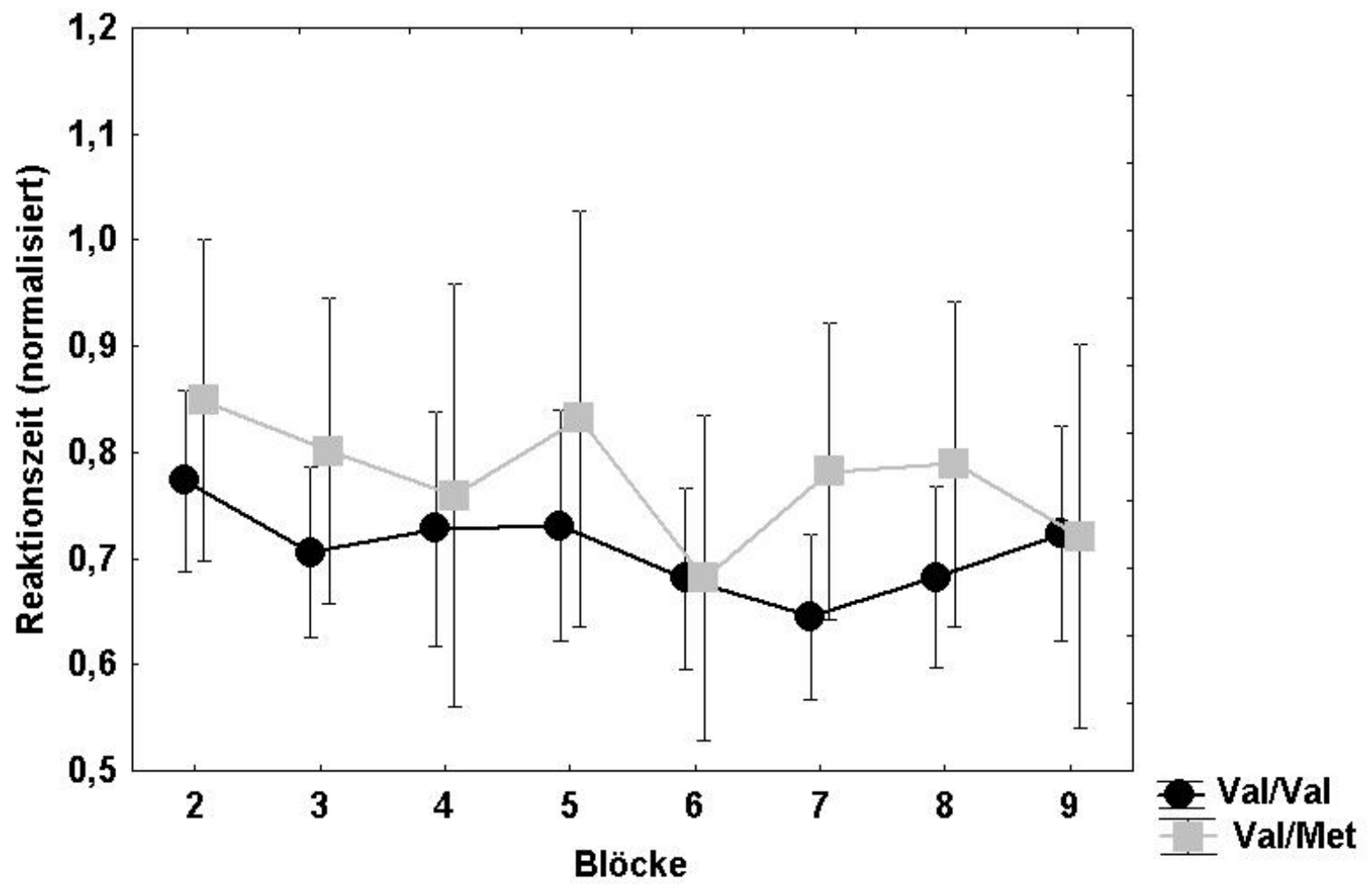

Abbildung 9: Vergleich der Reaktionszeiten während der kognitiven Aufgaben zwischen Val- und Met-AllelTrägern in der Testphase (oben) und der Retestphase (unten) 


\section{Diskussion}

Wie alle biologischen Daten unterliegen auch die bei transkraniellen Stimulationsmethoden gewonnenen Resultate hinsichtlich einer induzierten Neuroplastizität einer Varianz. So haben viele Arbeitsgruppen die Erfahrung gemacht, dass es sogenannte „gute“ und „schlechte“ Probanden gibt. Viele Faktoren spielen hierbei eine Rolle, so trägt die Entspannungsfähigkeit der Probanden sehr zu validen Ergebnissen bei. Neben absoluter Muskelentspannung ist auch kognitive Entlastung von Bedeutung für die Induktion plastischer Nacheffekte (Antal et al. 2007). Neue Hinweise bezüglich des Ansprechens von Probanden auf externe Stimulation und deren genetische Prädisposition haben eine weitere Grundlage zur Kontrolle interindividueller Effekte geschaffen. Unsere aktuellen Ergebnisse aus der durchgeführten retrospektiven Genotypisierungsstudie bestätigen und erweitern die Befunde von Cheeran et al. (2008) und Antal et al. (2010), die gezeigt haben, dass das Ansprechen auf externe Stimulation und die hervorgerufene Änderung der kortikalen Plastizität des primären motorischen Kortex mit dem Polymorphismus des BDNF-Genotyps zusammenhängt. Je nach genetischer Prädisposition läßt sich durch Auswahl eines Stimulationsverfahrens die individuell optimale Plastizitätsänderung erreichen.

\section{$\underline{\text { MEP-Mesungen }}$}

Bei nicht-genotypisierten gesunden Probanden erzeugt die cTBS einen hemmenden, die iTBS einen faszilitierenden Effekt auf die neuronale Plastizität (Huang et al. 2005). Bei Individuen mit dem Genotyp Val66Val hatte die iTBS einen günstigen Einfluss auf die MEPs für 30 Minuten, wobei dieser Nacheffekt reduziert oder sogar abwesend bei Trägern des Met-Allels war. Unsere Befunde bestätigen diese Daten und stehen in Einklang mit einer weiteren Studie, die die Rolle des BDNF-Polymorphismus in Antwort auf die rTMS bei 36 Patienten mit affektiver Störung (Bocchio-Chiavetto et al. 2008) untersucht hatte. Die Behandlung mit rTMS verbesserte signifikant die depressive Symptomatik bei homozygoten Val66ValTrägern im Vergleich zu Met-Trägern. Im Kontext mit den gegenwärtigen Daten ist es wahrscheinlich, dass die Met-Träger mit ihrer depressiven Symptomatik schlechter auf die Effekte der iTBS/rTMS ansprechen als Träger des Val66Val-Allels.

Die wichtigen neuen Kenntnisse dieser Arbeit sind die gegenläufigen Effekte der tDCS und der iTBS/tACS bei Individuen mit dem Val66Met-Allel. Hierbei war der Effekt der anodalen tDCS sogar besser bei Met66Val-Trägern (60 min) als bei Val66Val-Trägern. Zwei Studien hatten den Zusammenhang zwischen dem BDNF-Genotyp und den tDCS-Nacheffekten untersucht (Cheeran et al. 2008, Antal et al. 2010). In der ersten Studie wurde ein Protokoll 
angewendet, in dem eine zehnminütige kathodale tDCS von 900 unterschwelligen TMSPulsen mit $1 \mathrm{~Hz}$ gefolgt wurde. Hier hatte die kathodale tDCS die gleiche Wirkung einer LTD-ähnlichen Suppression auf die kortikale Aktivität bei allen Probanden. In der zweiten Studie konnte kein Unterschied zwischen Homo- und Heterozygoten direkt nach der Stimulation, sondern erst 20-50 Minuten später festgestellt werden.

Ähnlich wie bei der anodalen tDCS wurde auch hier eine Fazilitation nach tRNS entsprechend den Ergebnissen in einer nicht-genotypisierter Population (Terney et al. 2008) in beiden Gruppen beobachtet. Der tRNS-Nacheffekt scheint damit weniger empfindlich zu sein bezüglich der genetischen BDNF-Varianten verglichen mit dem anodalen Effekt, insbesondere aber gegenüber den TBS-Daten. Die tDCS modifiziert direkt das neuronale Transmembranpotential, und so die Entladungsrate der Neuronen (Bindman et al. 1964). Im Gegenteil dazu interferiert die tRNS vermutlich mit laufenden Oszillationen und neuronaler Aktivität im Gehirn durch Aktivierung von Natriumkanälen bei höherer Stimulationsfrequenz (Bromm 1968).

Bei der tACS konnten wir eine Erhöhung der kortikalen Exzitabilität feststellen. Die Val/ValTräger zeigten eine stärkere Erhöhung der MEP-Amplituden zum Zeitpunkt 30 Minuten.

Im Gegensatz zu diesen beiden Methoden, tDCS und tACS, die eher einen modulatorischen Effekt haben, besitzen rTMS/TBS und auch die PAS, die hier nicht untersucht wurde, eher einen direkten erregenden Effekt. Die PAS besteht in der Stimulation des Nervus medianus mit langsamer Geschwindigkeit und niedriger Frequenz in Kombination mit TMS über den kontralateralen M1. In Bezug auf die PAS zeigten die MEP-Amplituden keine signifikante Zunahme bei Probanden mit dem Val66Met-Allel (Cheeran et al. 2008). Ähnlich gab es im Hinblick auf TBS keine Zunahme (iTBS) oder Abnahme (cTBS) der MEP-Amplituden nach der Stimulation bei Trägern des Val66Met-Allels.

Diese Ergebnisse zeigen, dass modulatorische und erregende, oder bezogen auf eine induzierte Entladung von spinalen Motoneuronen und der damit verbundenen Muskelzuckung unterschwellige oder überschwellige Stimulation, Methoden auf unterschiedlichen Wegen ihre Wirkung und sich damit auch genetisch determiniert unterschiedlich entfalten. Die beiden Wege besitzen verschiedene prä- und postsynaptische Effekte, die unterschiedliche Antworten aufgrund des BDNF-Polymorphismus zeigen können und einen Effekt auf die BDNFSekretion haben können. Der BDNF entfaltet seinen Effekt auf die Sekretion von Neurotransmittern in den Synapsen durch präsynaptische Mechanismen (Tyler et al. 2002). Der BDNF modifiziert die Stärke der neuronalen Konnektivität durch Feinabstimmung der 
synaptischen Aktivität und verbessert das signal-to-noise-Verhältnis durch direkte Wirkung auf die präsynaptischen Endigungen. Zusätzlich zu diesen Mechanismen könnten wir auch vermuten, dass die verschiedenen Stimulationsarten unterschiedlich auf die Sekretion von proBDNF, abhängig von seinem primären molekularen hot-spot, wirken. Deshalb könnte auch das extrazelluläre Gleichgewicht zwischen proBDNF und mBDNF geändert werden (Brunoni et al. 2008, Missitzi et al. 2011).

\section{$\underline{\text { Kognitive Untersuchung }}$}

Die Ergebnisse zeigen weiter, dass Val/Val-Träger eine bessere kognitive Leistung aufweisen als Träger des Met-Allels sowohl in der Test- als auch in der Retest-Phase. Die Reaktionszeit der Val/Val-Trägern war besser in der Retest-Phase als die der Val/Met-Träger. In der TestPhase konnten wir keinen Unterschied in den Reaktionszeiten zwischen den beiden Gruppen feststellen.

Vorausgehende Untersuchungen haben gezeigt, dass BDNF-Polymorphismen sowohl anatomische wie auch funktionelle Auswirkungen in der gesunden menschlichen Population haben. Egan et al. (2003) konnten nachweisen, dass Met-Allel-Trägern im Vergleich zu Val66Val Probanden ein kleineres hippokampales Volumen und eine Verringerung der grauen Substanz im Frontallappen aufweisen. Zudem zeigen Met66Met homozygote Probanden ein eingeschränktes episodisches Gedächtnis, wohingegen Val66Met hererozygote Probanden eine eingeschränkte Wiedererkennung von visuellen Szenen in deklarativen Gedächtnistests aufwiesen. Hariri et al. (2003) berichteten, dass Met-Träger relativ zu ValHomozygoten Probanden eine verringerte hippokampale Aktivität sowohl während der Verschlüsselung als auch in Abrufprozessen bei der Durchführung eines deklarativen Gedächtnistestes hatten. Unsere Ergebnisse bestätigen diese Befunde (Paulus 2011).

In einer Studie wurde mittels sTMS gezeigt, dass der BDNF-Genotyp mit dynamischen Veränderungen in der Erregbarkeit des M1 im Anschluss an einer motorischen Aktion assoziiert ist. Die Autoren fanden heraus, dass bei gesunden Probanden mit dem Val66MetPolymorphismus die MEP-Amplitudenzunahme trainingsabhängig reduziert war. Allerdings wurde auch festgestellt, dass der Val66Met-Polymorphismus nicht mit Änderungen im Arbeitsgedächtnis bei Erwachsenen assoziiert ist (Hansell et al. 2007). Diese Studie untersuchte eine große Probe $(n=785)$ an erwachsenen Zwillingspaaren und Geschwistern. Eine Reihe von Messungen (ereignisbezogene, generelle Leistung und Reaktionszeit), erhalten durch eine verzögerte Reaktion bei arbeitsgedächtnisbetreffenden Aufgaben, zeigten 
keine Beziehung zwischen dem Genotyp und der Arbeitsgedächtnisleistung in den vorgegebenen Aufgaben.

Es gibt auch vorläufige Studien, die die Rolle des BDNF und des motorischen Verhaltens zeigen. In einer Studie von Ploughman et al. (2009) zeigten Ratten eine signifikante Erholung nach einem lokalen Schlaganfall. Dies wurde durch Aufgaben in Zusammenhang mit Treppensteigen beobachtet. Man erreicht eine Erhöhung des BDNF-Spiegels bei Übungen und Exposition in einer günstigen Umgebung sowohl in Tier- als auch in Menschenmodellen (Ploughman et al. 2009, Zoladz et al. 2008). Studien in Tiermodellen schlagen hier das Vorhandensein einer Beziehung zwischen der motorischen Erholungsfähigkeit und dem BDNF-Spiegel während einer Rehabilitation nach physikalischem Trauma vor. Dies könnte auch auf menschliche Rehabilitationsmodelle nach Verletzungen übertragbar sein. Andere Studien berichten, dass BDNF die synaptische Stabilität durch die Modulation von neuronalen Endladungsmustern fördert. Dies weist darauf hin, dass BDNF eine integrale Rolle in der Neuordnung der synaptischen Schaltkreise während einer Rehabilitation nach einer Verletzung spielen könnte (Davis-López de Carrizosa et al. 2009).

\section{Zusammenfassung und Ausblick}

Verschiedene Studien fanden heraus, dass Probanden unterschiedlich auf rTMS/tDCSProtokolle reagieren. Mehrere mögliche Gründe dafür sind schon beschrieben worden, wie zum Beispiel das Alter der Probanden (Müller-Dahlhaus et al. 2008), das Geschlecht (Kuo et al. 2006), der zirkadiane Rhythmus (Sale et al. 2008), der weibliche Zyklus (Inghilleri et al. 2004) oder die Vorgeschichte von Gehirnaktivierungen (Lang et al. 2004, Silvanto et al. 2008). In der Tat spielt der Präinnervationsstatus eine zentrale Rolle in der Induktion von plastischen Nacheffekten (Antal et al. 2007). In Einklang mit anderen Studien und unserer aktuellen Arbeit ist der Polymorphismus im BDNF-Gen ein wichtiger Baustein in der direkten Beeinflussung von synaptischer Plastizität bei Erwachsenen. Darüber hinaus stellt sich die Frage, welcher Polymorphismus für die Unwirksamkeit der rTMS/tDCS in der Therapie von bestimmten neurologischen und psychiatrischen Erkrankungen, wie zum Beispiel bei Depressionen, verantwortlich ist. Sicherlich müssen neben dem Val66Met-SNP weitere Polymorphismusvarianten (nicht nur die Allele) betrachtet werden, die auch verantwortlich sein können für diese Reaktionsunterschiede, die wir in Form von Stimulationsnacheffekten feststellen können (Klein et al. 2007). Außerdem spielen nicht nur die BDNF-Varianten eine Rolle in der Stabilität und Amplitude der MEPs, sondern auch das Zusammenspiel anderer 
Gene innerhalb gleicher Loci. Das ganze Zusammenspiel ist vermutlich verantwortlich für die poststimulatorischen Nacheffekte. Bis jetzt wurde von 100 Genen berichtet, die die Funktion des menschlichen Gehirns und die Kognition beeinflussen können (de Geus et al. 2008). Zusätzlich könnte die Beteiligung von Neurotransmitterrezeptoren und ihre Assoziation mit bestimmten Allelen verantwortlich sein für die unterschiedlichen Protokollergebnisse. Weiterhin ist nicht bekannt, welche BDNF-Rezeptoren (TrkB und p75) im Kortex exprimiert werden.

Die Begrenzung unserer Studie liegt im retrospektiven Charakter der durchgeführten Analyse. Deshalb war Zahl, Alter und die Geschlechtsverteilung auf die homo- und heterozygoten Gruppen nicht statistisch ausreichend valide zu untersuchen. Die Probanden waren jedoch innerhalb der gleichen Altersgruppe verteilt und das Verhältnis Frau/Mann war gleich zwischen den beiden Genotyppopulationen. Deshalb sind weitere prospektive Studien mit noch größeren Zahlen notwendig. Unsere Daten bekräftigen die Rolle des BDNF als wichtigen Modulator der kortikalen Plastizität beim Menschen. Weitere Studien sind auch unter physiologischen Aspekten erforderlich, um Umfang und Art des direkten Einflusses von BDNF und seine unterschiedlichen Mechanismen auf die neuronale Plastizität genauer zu verstehen. Momentan existiert nur eine Studie, die den Effekt von TMS auf die Expression von c-Fos und BDNF gezeigt hat. Diese Studie unterstützt die kausative Beziehung zwischen BDNF und elektrischer Stimulation (Zhang et al. 2007). 


\section{Literaturverzeichnis}

Acheson A, Barker PA, Alderson RF, Miller FD, Murphy RA (1991): Detection of brain derived neurotrophic factor-like activity in fibroblasts and Schwann cells: Inhibition by antibodies to NGF. Neuron $\underline{7}$ (2), 265-275

Alderson RF, Alterman AL, Barde YA, Lindsay RM (1990): Brain-derived neurotrophic factor increases survival and differentiated functions of rat septal cholinergic neurons in culture. Neuron $\underline{5}(3)$, 297-306

Ambrus GG, Paulus W, Antal A (2010): Cutaneous perception thresholds of electrical stimulation methods: comparison of tDCS and tRNS. Clin Neurophysiol 121(11),1908-14

Antal A, Terney D, Poreisz C and Paulus W (2007): Towards unravelling task-related modulations of neuroplastic changes induced in the human motor cortex. Eur J Neurosci 26, 2687-2691

Antal A, Brephol N, Poreisz C, Boros K, Csifcsak G, Paulus W (2008): Transcranial direct current stimulation over somatosensory cortex decreases experimentally induced acute pain perception. Clin J Pain 24, 56-63

Antal A, Chaieb L, Moliadze V, Monte-Silva K, Poreisz C, Thirugnanasambandam N, Nitsche MA, Shoukier M, Ludwig H, Paulus W (2010): Brain-derived neurotrophic factor (BDNF) gene polymorphisms shape cortical plasticity in humans. Brain Stimul $\underline{3}(4)$, 230-7

Ardolino G, Bossi B, Barbieri S, Priori A (2005): Non-synaptic mechanisms underlie the after-effects of cathodal trancutaneous direct current stimulation of the humain brain. J Physiol $\underline{568}$, 653-663

Barde YA, Edgar D, Thoenen H (1982): Purification of a new neurotrophic factor from mammalian brain. EMBO J 1(5), 549-553

Barker AT, Jalinous R, Freeston IL (1985): Non-invasive magnetic stimulation of the human motor cortex. Lancet 1985,1, 1106-1107

Bertram L, McQueen MB, Mullin K, Blacker D, Tanzi RE (2007): Systematic meta-analyses of Alzheimer disease genetic association studies: The AlzGene database. Nat Genet 39, 17-23 Bindman LJ, Lippold OCJ, Redfearn JWT (1964): The action of brief polarizing currents on the cerebral cortex of the rat (1) during current flow and (2) in the production of long-lasting after-effects. J Physiol 172, 369-382 
Blum R, Kafitz KW, Konnerth A (2002): Neurotrophin-evoked depolarization requires the sodium channel $\mathrm{Na}(\mathrm{V}) 1.9$. Nature $\underline{419}(6908), 687-693$

Bocchio-Chiavetto L, Miniussi C, Zanardini R, Gazzoli A, Bignotti S, Specchia C, Gennarelli M (2008): 5-HTTLPR and BDNF Val66Met polymorphisms and response to rTMS treatment in drug resistant depression. Neurosci Lett $\underline{437}, 130-1344$

Bolton MM, Pittman AJ, Lo DC (2000): Brain-Derived Neurotrophic Factor Differentially Regulates Excitatory and Inhibitory Synaptic Transmission in Hippocampal Cultures. J Neurosci 20(9), 3221-3232

Bromm B (1968): Die Natrium-Gleichrichtung der unterschwellig erregten Membran in der quantitativen Formulierung der Ionentheorie. Pflügers Arch 302, 233-244

Brunoni AR, Boggio PS, Fregni F (2008): Can the 'yin and yang' BDNF hypothesis be used to predict the effects of rTMS treatment in neuropsychiatry? Med Hypotheses $\underline{71}$, 279-282

Calabresi P, Napolitano M, Centonze D, Marfia GA, Gubellini P, Teule MA, Berretta N, Bernardi G, Frati L, Tolu M, Gulino A (2000): Tissue plasminogen activator controls multiple forms of synaptic plasticity and memory. Eur J Neurosci 12(3), 1002-1012

Cartwright M, Mikheev AM, Heinrich G (1994): Expression of neurotrophin genes in human fibroblasts: differential regulation of the brain-derived neurotrophic factor gene. Int J Dev Neurosci 12(8), 685-693

Chaieb L, Antal A, Paulus W (2011): Transcranial Alternating Current Stimulation in the low kHz Range increases motor cortex excitability. Restor Neurol Neurosci 29, 167-75

Chao HM, Kao HAT, Porton B (2007): BDNF Val66Met variant and age of onset in schizophrenia. Am J Met Genet Neuropsychiatr Genet 147B (4), 505-506

Cheeran B, Talelli P, Mori F, Koch G, Suppa A, Edwards M, Houlden H, Bhatia K, Greenwood R, Rothwell JC (2008): A common polymorphism in the brain-derived neurotrophic factor gene (BDNF) modulates human cortical plasticity and the response to rTMS. J Physiol 586: 5717-5725

Chen CM, Chen IC, Chang KH, Chen YC, Lyu RK, Liu YT, Hu FJ, Chao CY, Lee-Chen GJ, Wu YR (2007): Nuclear receptor NR4A2 IVS6 +18insG and brain derived neurotrophic factor (BDNF) V66M polymorphisms and risk of Taiwanese Parkinson's disease. Am J Med Genet B Neuropsychiatr Genet 144(4), 458-462 
Chen J, Lipska BK, Halim N, Ma QD, Matsumoto M, Melhem S, Kolachana BS, Hyde TM, Hermann MM, Apud J et al. (2004): Functional analysis of genetic variation in catecholOmethyltransferase (COMT): effects on mRNA, protein, and enzyme activity in postmortem human brain. Am J Hum Genet 포, 807-821

Chen R, Seitz RJ (2001): Changing cortical excitability with low-frequency magnetic stimulation. Neurology 57(3), 379-80

Chen Z-Y, Ieraci A, Teng H, Dall H, Meng C-X, Herrera DG, Nykjaer A, Hempstead BL, Lee FS (2005): Sortilin controls intracellular sorting of brain-derived neurotrophic factor to the regulated secretory pathway. J Neurosci $\underline{25}$, 6156-6166

Classen J, Wolters A, Stefan K, Wycislo M, Sandbrink F, Schmidt A, Kunesch E (2004): Paired associative stimulation. Suppl Clin Neurophysiol 무, 563-569

Cooke SF, Bliss TVP (2006): Plasticity in the human central nervous system. Brain $\underline{129}$, 1659-1673

Creutzfeldt OD, Fromm GH, Kapp H (1962): Influence of transcortical d-c current on cortical neuronal activity. Exp Neurol $\underline{5}, 436-452$

Cunha C, Brambilla R, Thomas KL (2010): A simple role for BDNF in learning and memory? Front Mol Neurosci $\underline{3}, 1-14$

Davis-López de Carrizosa MA, Morado-Díaz CJ, Tena JJ, Benítez-Temiño B, Pecero ML, Morcuende SR, de la Cruz RR, Pastor AM (2009): Complementary actions of BDNF and neurotrophin-3 on the firing patterns and synaptic composition of motoneurons. J Neurosci $\underline{29}, 575-587$

De Frias CM, Marklund P, Eriksson E, Larsson A, Oman L, Annerbrink K, Backman L, Nilsson L-G, Nyberg L (2010): Influence of COMT gene polymorphism on fMRI-assessed sustained and transient activity during a working memory task. J Cogn Neurosci 22, 16141622

de Geus E, Goldberg T, Boomsma DI und Posthuma D (2008): Imaging the genetics of brain structure and function. Biol Psychol $\underline{79}$, 1-8

Di Lazzaro V, Pilato F, Saturno E, Oliviero A, Dileone M, Mazzone P, Insola A, Tonali PA, Ranieri F, Huang YZ et al. (2005): Theta-burst repetitive transcranial magnetic stimulation suppresses specific excitatory circuits in the human motor cortex. J Physiol $\underline{565}$, 945-950 
Egan MF, Kojima M, Callicott JH, Goldberg TE, Kolachana BS, Bertolino A, Zaitsev E, Gold B, Goldman D, Dean M, Lu B, Weinberger DR (2003): The BDNF val66met polymorphism affects activity-dependent secretion of BDNF and human memory and hippocampal function. Cell $\underline{112}$, 257-269

Engel AK, Fries P, Singer W (2001): Dynamic predictions: oscillations and sy nchrony in topdown processing. Nat Rev Neurosci 2 , 704-16

Erickson KI, Kim JS, Suever BL, Voss MW, Francis BM, Kramer AF (2008): Genetic contributions to age-related decline in executive function: a 10-year longitudinal study of COMT and BDNF polymorphisms. FNHUM 2, 11 doi:103389/neuro090112008

Finkbeiner S, Tavazoie SF, Maloratsky A, Jacobs KM, Harris KM, Greenberg ME (1997): CREB: a major mediator of neuronal neurotrophin responses. Neuron 19(5), 1031-1047

Fitzgerald PB, Benitez J, Oxley T, Daskalakis JZ, de Castella AR, Kulkarni J (2005): A study of the effects of lorazepam and dextromethorphan on the response to cortical $1 \mathrm{~Hz}$ repetitive transcranial magnetic stimulation. Neuroreport 8,16(13), 1525-8

Franca M, Koch G, Mochizuki H, Huang YZ, Rothwell JC (2006): Effects of theta burst stimulation protocols on phosphene threshold. Clin Neurophysiol 117, 1808-1813

Fregni F, Thome-Souza S, Nitsche MA, Freedman SD, Valente KD, Pascual-Leone A (2006a): A controlled clinical trial of cathodal DC polarization in patients with refractory epilepsy. Epilepsia 47, 335-342

Fregni F, Gimenes R, Valle AC, Ferreira MJ, Rocha RR, Natalle L, Bravo R, Rigonatti SP, Freedman SD, Nitsche MA et al. (2006b): A randomized, sham-controlled, proof-of principle study of transcranial direct stimulation for the treatment of pain in fibromyalgia. Arthritis Rheum 느, 3988-3998

Fritsch B, Reis J, Martinowich K, Schambra HM, Ji Y, Cohen LG, Lu B. (2010): Direct current stimulation promotes BDNF-dependent synaptic plasticity: potential implications for motor learning. Neuron $\underline{66}, 198-204$

Gartside IB (1968): Mechanisms of sustained increases of firing rate of neurones in the rat cerebral cortex after polarization: Reverberating circuits or modification of synaptic conductance? Nature 220, 383-384

Goggi J, Pullar IA, Carney SL, Bradford HF (2002): Modulation of neurotransmitter release induced by brain-derived neurotrophic factor in rat brain striatal slices in vitro. Brain Res $\underline{941}$, $34-42$ 
Goldberg TE, Iudicello J, Russo C, Elvevåg B, Straub R, Egan MF, Weinberger DR (2008): BDNF Val66Met polymorphism significantly affects d' in verbal recognition memory at short and long delays. Biol Psychol 77(1), 20-4

Greene LA, Kaplan DR (1995): Early events in neurotrophin signalling via Trk and p75 receptors. Curr Opin Neurobiol $\underline{5}(5), 579-587$

Hansell NK, James MR, Duffy DL, Birley AJ, Luciano M, Geffen GM, Wright MJ, Montgomery GW, Martin NG (2007): Effect of the BDNF V166M polymorphism on working memory in healthy adolescents. Genes Brain Behav $\underline{6}$, 260-268

Hariri AR, Goldberg TE, Mattay VS, Kolachana BS, Callicott JH, Egan MF, Weinberger DR (2003): Brain-derived neurotrophic factor val66met polymorphism affects human memoryrelated hippocampal activity and predicts memory performance. J Neurosci 23: 6690-6694

Harris SE, Fox H, Wright AF, Hayward C, Starr JM, Whalley LJ, Deary IJ (2006): The brainderived neurotrophic factor Val66Met polymorphism is associated with age-related change in reasoning skills. Mol Psychiatry $\underline{11}(5), 505-513$

Hattori Y, Moriwaki A, Hori Y (1990): Biphasic effects of polarizing current on adenosinesensitive generation of cyclic AMP in rat cerebral cortex. Neurosci Lett $\underline{116}$, 320-324

Hebb DO: The organization of behaviour. John Wiley Sons, New York 1949

Hedden T, Gabrieli JD (2004): Insights into the ageing mind: A view from cognitive neuroscience. Nat Rev Neurosci $\underline{5}, 87-96$

Henneberger C, Jüttner R, Rothe T, Grantyn R (2002): Postsynaptic action of BDNF on GABAergic synaptic transmission in the superficial layers of the mouse superior colliculus. $\mathrm{J}$ Neurophysiol $\underline{88}(2), 595-603$

Huang YZ, Edwards MJ, Rounis E, Bhatia KP, Rothwell JC (2005): Theta burst stimulation of the human motor cortex. Neuron $\underline{45}$ : 201-206

Inghilleri M, Conte A, Curr`a A, Frasca V, Lorenzano C, Berardelli A (2004) : Ovarian hormones and cortical excitability. An rTMS study in humans. Clin Neurophysiol $\underline{115}, 1063-$ 1068

Islam N, Aftabuddin M, Moriwaki A, Hattori Y, Hori Y (1995a): Increase in the calcium level following anodal polarization in the rat brain. Brain Res $\underline{684}$, 206-208 
Islam N, Moriwaki A, Hattori Y, Hayashi Y, Lu YF, Hori Y (1995b): c-Fos expression mediated by N-methyl-D-aspartate receptors following anodal polarization in the rat brain. Exp Neurol 133, 25-31

Islam N, Aftabuddin M, Moriwaki A, Hori Y (1997): Effects of anodal polarization on protein kinase Cgamma (PKCgamma) in the rat brain. Indian J Physiol Pharmacol 41, 204-210

Kafitz KW, Rose CR, Thoenen H, Konnerth A (1999): Neurotrophin-evoked rapid excitation through TrkB receptors. Nature $\underline{401}$, 918-921

Kanai R, Chaieb L, Antal A, Walsh V, Paulus W (2008): Frequency-dependent electrical stimulation of the visual cortex. Curr Biol $\underline{18}, 1839-1843$

Kandel ER, Schwartz JH, Jessel TM: Neurowissenschaften - Eine Einfuhrung. Spektrum Akademischer Verlag: Berlin Heidelberg 1996

Kleim JA, Chan S, Pringle E, Schallert K, Procaccio V, Jimenez R, Cramer SC (2006): BDNF val66met polymorphism is associated with modified experience-dependent plasticity in human motor cortex. Nat Neurosci $\underline{9}, 735-737$

Klein TA, Neumann J, Reuter M, Hennig J, von Cramon DY, Ullsperger M (2007): Genetically Determined Differences in Learning from Errors. Science 318, 1642-1645

Korte M: Zelluläre Grundlangen von Lern- und Gedächtnisvorgängen, Tätigkeitsbericht, MPI für Neurobiologie, Abteilung für Zelluläre und Systemneurobiologie, Martinsried 2004

Kuo MF, Paulus W und Nitsche MA (2006): Sex differences in cortical neuroplasticity in humans. Neuroreport $\underline{17}, 1703-7$

Lang N, Siebner HR, Ernst D, Nitsche MA, Paulus W, Lemon RN, Rothwell JC (2004): Preconditioning with transcranial direct current stimulation sensitizes the motor cortex to rapid-rate transcranial magnetic stimulation and controls the direction of after-effects. Biol Psychiatry $\underline{56}$, 634-639

Larson J, Lynch G (1986): Induction of synaptic potentiation in hippocampus by patterned stimulation involves two events. Science 232, 985-988

Laske C, Eschweiler GW (2006): Brain-derived neurotrophic factor. Vom Nervenwachstumsfaktor zum Plastizitätsmodulator bei kognitiven Prozessen und psychischen Erkrankungen. Nervenarzt 77 (5), 523-537 
Lee J, Laurin N, Crosbie J, Ickowicz A, Pathare T, Malone M, Tannock R, Kennedy JL, Schachar R, Barr CL (2007): Association study of the brainderived neurotropic factor (BDNF) gene in attention deficit hyperactivity disorder. Am J Med Genet B Neuropsychiatr Genet $\underline{144(8), 976-981}$

Lee R, Kermani P, Teng KK, Hempstead BL (2001): Regulation of cell survival by secreted proneurotrophins. Science $\underline{294}$ (5548), 1945-1948

Leibrock J, Lottspeich F, Hohn A, Hofer M, Hengerer B, Masiakowski P, Thoenen H, Barde YA (1989): Molecular cloning and expression of brainderived neurotrophic factor. Nature 341, 149-152

Lessmann V und Heumann R (1998): Modulation of unitary glutamatergic synapses by neurotrophin-4/5 or brain-derived neurotrophic factor in hippocampal microcultures: presynaptic enhancement depends on preestablished paired-pulse facilitation. Neuroscience 86(2), 399-413

Levine ES, Dreyfus CF, Black IB, Plummer MR (1996): Selective role for trkB neurotrophin receptors in rapid modulation of hippocampal synaptic transmission. Brain Res Mol Brain Res $\underline{38}$ (2), 300-303

Li YX, Xu Y, Ju D, Lester HA, Davidson N, Schuman EM (1998): Expression of a dominant negative TrkB receptor, T1, reveals a requirement for presynaptic signaling in BDNF-induced synaptic potentiation in cultured hippocampal neurons. Proc Natl Acad Sci U S A 95(18), 10884-10889

Lian J, Bikson M, Sciortino C, Stacey WC, Durand DM (2003): Local suppression of epileptiform activity by electrical stimulation in rat hippocampus in vitro. J Physiol $\underline{547,427-}$ 434

Liebetanz D, Klinker F, Hering D, Koch R, Nitsche MA, Potschka H, Löscher W, Paulus W, Tergau F (2006): Anticonvulsant effects of transcranial direct-current stimulation (tDCS) in the rat cortical ramp model of focal epilepsy. Epilepsia 47, 1216-1224

Lindenberger U, Nagel IE, Chicherio C, Li S-C, Heekeren HR, Backman L (2008): Agerelated decline in brain resources modulates genetic effects on cognitive functioning. FNHUM 2, 234-244

Linnarsson S, Bjorklund A, Ernfors P (1997): Learning deficit in BDNF mutant mice. Eur J Neurosci $\underline{9}, 2581-2587$ 
Liu QR, Lu L, Zhu XG, Gong JP, Shaham Y, Uhl GR (2006): Rodent BDNF genes, novel promoters, novel splice variants, and regulation by cocaine. Brain Res 1067(1), 1-12

Lommatzsch M, Braun A, Mannsfeldt A, Botchkarev VA, Botchkareva NV, Paus R, Fischer A, Lewin GR, Renz H (1999): Abundant production of brainderived neurotrophic factor by adult visceral epithelia. Implications for paracrine and target-derived Neurotrophic functions. Am J Pathol 155(4),1183-1193

Lovden M, Backman L, Lindenberger U, Schaefer S, Schmiedek F (2010): A theoretical framework for the study of adult cognitive plasticity. Psychol Bull 136, 659-679

McHughen SA, Rodriguez PF, Kleim JA, Kleim ED, Marchal Crespo L, Procaccio V, Cramer SC (2010): BDNF val66met polymorphism influences motor system function in the human brain. Cereb Cortex 20, 1254-1262

Merton PA, Morton HB (1980): Stimulation of the cerebral cortex in the intact human subject. Nature 285, 227

Missitzi J, Gentner R, Geladas N, Politis P, Karandreas N, Classen J, Klissouras V (2011): Plasticity in human motor cortex is in part genetically determined. J Physiol 589(Pt 2):297306

Miyajima F, Ollier W, Mayes A, Jackson A, Thacker N, Rabbitt P, Pendleton N, Horan M, Payton A (2008): Brain-derived neurotrophic factor polymorphism Val66Met influences cognitive abilities in the elderly. Genes Brain Behav 7(4), 411-7

Mochizuki H, Franca M, Huang YZ, Rothwell JC (2005): The role of dorsal premotor area in reaction task: comparing the "virtual lesion" effect of paired pulse or theta burst transcranial magnetic stimulation. Exp Brain Res 167, 414-421

Moliadze V, Antal A, Paulus W (2010): Boosting brain excitability by transcranial high frequency stimulation in the ripple range. J Physiol 588(24), 4891- 4904

Mori F, Codecà C, Kusayanagi H, Monteleone F, Boffa L, Rimano A, Bernardi G, Koch G, Centonze D (2010): Effects of intermittent theta burst stimulation on spasticity in patients with multiple sclerosis. Eur J Neurol 17(2), 295-300

Mowla SJ, Farhadi HF, Pareek S, Atwal JK, Morris SJ, Seidah NG, Murphy RA (2001): Biosynthesis and post-translational processing of the precursor to brain-derived neurotrophic factor. J Biol Chem 276(16), 12660-12666 
Muragaki Y,Timothy N,Leight S, Hempstead BL, Chao MV, Trojanowski JQ, Lee VMY (1995): Expression of trk receptors in the developing and adult human central and peripheral nervous system. J Comp Neurol 356(3), 387-397

Müller-Dahlhaus J, Orekhov Y, Liu Y und Ziemann U (2008): Interindividual variability and age-dependency of motor cortical plasticity induced by paired associative stimulation. Exp Brain Res 187, 467-475

Nagel IE, Chicherio C, Li S-C, Nyberg L, von Oertzen T, Sander T, Vilringer A, Heekeren HR, Backman L, Lindenberger U (2008): Human aging magnifies genetic effects on executive functioning and working memory. Front Hum Neurosci 2 , 1-8

Nitsche MA, Paulus W (2000): Excitability changes induced in the human motor cortex by weak transcranial direct current stimulation. J Physiol $\underline{527,633-639}$

Nitsche MA, Paulus W (2001): Sustained excitability elevations induced by transcranial DC motor cortex stimulation in humans. Neurology $\underline{57,1899-1901}$

Nitsche MA, Paulus W: Transkranielle Gleichstromstimulation. In: Das TMS-Buch: Transkranielle Magnetstimulation, hrsg. v. Siebner HR, Ziemann V; Springer Medizin Verlag Heidelberg 2007, 533-541

Nitsche MA, Nitsche MS, Klein CC, Tergau F, Rothwell JC, Paulus W (2003): Level of action of cathodal DC polarisation induced inhibition of the human motor cortex. Clin Neurophysiol 114, 600-604

Nitsche MA, Cohen LG, Wassermann EM, Priori A, Lang N, Antal A, Paulus W, Hummel F, Boggio PS, Fregni F et al. (2008): Transcranial direct current Stimulation: State of the Art 2008. Brain Stimulat 1 , 206-223

Nonomura T, Hatanaka H (1992): Neurotrophic effect of brain-derived neurotrophic factor on basal forebrain cholinergic neurons in culture from postnatal rats. Neurosci Res $\underline{14(3), 226-}$ 233

Pang PT, Teng HK, Zaitsev E, Woo NT, Sakata K, Zhen S, Teng KK, Yung WH, Hempstead BL, Lu B (2004): Cleavage of proBDNF by tPA/plasmin is essential for long-term hippocampal plasticity. Science $\underline{306}$, 487-491

Papassotiropoulos A, Stephan DA, Huentelman MJ, Hoerndli FJ, Craig DW, Pearson JV, Huynh KD, Brunner F, Corneveaux J, Osborne D et al. (2006): Common Kibra alleles are associated with human memory performance. Science $\underline{314}$, 475-8 
Patterson SL, Pittenger C, Morozov A, Martin KC, Scanlin H, Drake C, Kandel ER (2001) Some forms of cAMP-mediated long-lasting potentiation are associated with release of BDNF and nuclear translocation of phospho-MAP kinase. Neuron 32(1), 123-140

Paulus W 2011: Transcranial stimulation techniques: which genetics is the best for which purpose? J Physiol 589(Pt6), 1245

Pearson-Fuhrhop KM, Kleim JA, Cramer SC (2009): Brain plasticity and genetic factors. Top Stroke Rehabil 16, 282-299

Pezawas L, Verchinski BA, Mattay VS, Callicott JH, Kolachana BS, Straub RE, Egan MF, Meyer-Lindenberg A, Weinberger DR (2004): The brain-derived neurotrophic factor val66met polymorphism and variation in human cortical morphology. J Neurosci 24, 1009910102

Pinel JPJ: Biopsychologie. Spektrum Akademischer Verlag, Heidelberg Berlin 2001

Ploughman M, Windle V, MacLellan CL, White N, Doré JJ, Corbett D (2009): Brain-derived neurotrophic factor contributes to recovery of skilled reaching after focal ischemia in rats. Stroke $\underline{40}, 1490-1495$

Poreisz C, Boros K, Antal A, Paulus W (2007): Safety aspects of transcranial direct current stimulation concerning healthy subjects and patients. Brain Res Bull 72, 208-214

Poreisz C, Paulus W, Moser T, Lang N. (2009): Does a single session of theta-burst transcranial magnetic stimulation of inferior temporal cortex affect tinnitus perception? BMC Neurosci $\underline{10}, 54$

Pruunsild P, Kazantseva A, Aid T, Palm K, Timmusk T (2007): Dissecting the human BDNF locus: bidirectional transcription, complex splicing, and multiple promoters. Genomics $\underline{90}(3)$, 397-406

Purpura DP, McMurtry JG (1965): Intracellular activities and evoked Potenzial changes during polarization of motor cortex. J Neurophysiol 28, 166-185

Reichardt LF, Farinas I: Neurotrophic factrors and their receptors: roles in neuronal development and function. In: Cowan WM, Jessell TM, Zipursky SL (Hrsg.); Molecular and cellular approaches to neuronal development. Oxford Univ. Press New York 1997, 220-263

Ribeiro L, Busnello JV, Cantor RM, Whelan F, Whittaker P, Deloukas P, Wong ML, Licinio J (2007): The brain-derived neurotrophic factor rs6265 (Val66Met) polymorphism and depression in Mexican-Americans. Neuroreport 18(12),1291-1293 
Rosenthal A, Goeddel DV, Nguyen T, Martin E, Burton LE, Shih A, Laramee GR, Wurm F, Mason A, Nikolics K (1991): Primary structure and biological activity of human brainderived neurotrophic factor. Endocrinology $\underline{129}$, 1289-1294

Rothwell JC, Hallett M, Berardelli A, Eisen A, Rossini P, Paulus W (1999): Magnetic stimulation: motor evoked potentials: the International Federation of Clinical Neurophysiology. Electroencephalogr Clin Neurophysiol Suppl 2: 97-103

Sala R, Viegi A, Rossi FM, Pizzorusso T, Bonanno G, Raiteri M, Maffei L (1998): Nerve growth factor and brain-derived neurotrophic factor increase neurotransmitter release in the rat visual cortex. Eur J Neurosci 10(6): 2185-2191

Sale MV, Ridding MC und Nordstrom MA (2008): Cortisol inhibits neuroplasticity induction in human motor cortex. J Neurosci 28, 8285-8293

Sanes und Donoghue (2000): Plasticity and primary motor cortex. Annu Rev Neurosci $\underline{23}$, 393-415

Schaper K, Kolsch H, Popp J, Wagner M, Jessen F (2008): KIBRA gene variants are associated with episodic memory in healthy elderly. Neurobiol Aging 29, 1123-1125

Schimmelmann BG, Friedel S, Dempfle A, Warnke A, Lesch KP, Walitza S, Renner TJ, Romanos M, Herpertz-Dahlmann B, Linder M et al. (2007): No evidence for preferential transmission of common valine allele of the Val66Met polymorphism of the brain-derived neurotrophic factor gene (BDNF) in ADHD. J Neural Transm 114(4), 523-526

Schulte-Herbrüggen O, Braun A, Rochlitzer S, Jockers-Scherübl MC, Hellweg R (2007): Neurotrophic factors-a tool for therapeutic strategies in neurological, neuropsychiatric and neuroimmunological diseases? Curr Med Chem 14(22), 2318-2329

Seger CA, Poldrack RA, Prabhakaran V, Zhao M, Glover GH, Gabrieli JDE (2000): Hemispheric asymmetries and individual differences in visual concept learning as measured by functional MRI. Neuropsychologia $\underline{38}, 1316-24$

Seidah NG, Benjannet S, Pareek S, Chretien M, Murphy RA (1996): Cellular processing of the neurotrophin precursors of NT3 and BDNF by the mammalian proprotein convertases. FEBS Lett $\underline{379}$, 247-250

Siebner HR, Ziemann U: Das TMS-Handbuch Transkranielle Magnetstimulation. Springer Medizin Verlag, Heidelberg 2007 
Siebner HR, Lang N, Rizzo V, Nitsche MA, Paulus W, Lemon RN, Rothwell JC (2004): Preconditioning of low-frequency repetitive transcranial magnetic stimulation with transcranial direct current stimulation: Evidence for homeostatic plasticity in the human motor cortex. J Neurosci 24, 3379-3385

Silva G, Miksad R, Freedman SD, Pascual-Leone A, Jain S, Gomes DL, Amancio EJ, Boggio PS, Correa CF, Fregni F (2007): Treatment of cancer pain with non-invasive brain Stimulation. J Pain Symptom Manage 34, 342-345

Silvanto J, Muggleton N und Walsh V (2008): State-dependency in brain stimulation studies of perception and cognition. Trends Cogn Sci 12, 447-454

Stefan K, Kunesch E, Cohen LG, Benecke R, Classen J (2000): Induction of plasticity in the human motor cortex by paired associative stimulation. Brain $\underline{123}$, 572-584

Stefan K, Wycislo M, Classen J (2004): Modulation of associative human motor cortical plasticity by attention. J Neurophysiol $\underline{92}, 66-72$

Talelli P, Greenwood RJ, Rothwell JC (2007): Exploring Theta Burst Stimulation as an intervention to improve motor recovery in chronic stroke. Clin Neurophysiol 118, 333-342

Terney D, Bergmann I, Poreisz C, Chaieb L, Boros K, Nitsche MA, Paulus W, Antal A (2008): Pergolide increases the efficacy of cathodal direct current stimulation to reduce the amplitude of laser-evoked potentials in humans. J Pain Symptom Manage 36(1), 79-91

Tyler WJ, Perrett SP und Pozzo-Miller LD (2002): The role of neurotrophins in neurotransmitter release. Neuroscientist $\underline{8}, 524-531$

Vaynman S, Gomez-Pinilla F (2006): Revenge of the "sit": how lifestyle impacts neuronal and cognitive health through molecular systems that interface energy metabolism with

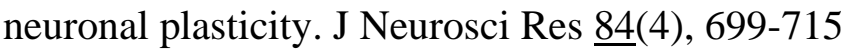

Walker JC, Murdoch JM (1957): Cycloserine in the treatment of pulmonary tuberculosis. A report on toxicity. Tubercle $\underline{38}, 297$

Watanabe Y, Muratake T, Kaneko N, Nunokawa A, Someya T (2006): No association between the brain-derived neurotrophic factor gene and schizophrenia in a Japanese population. Schizophr Res $\underline{84}(1), 29-35$

Webster MJ, Weickert CS, Herman MM, Kleinman JE (2002): BDNF mRNA expression during postnatal development, maturation and aging of the human prefrontal cortex. Brain Res Dev Brain Res 139(2), 139-50 
Weinstock-Guttman B, Zivadinov R, Tamaño-Blanco M, Abdelrahman N, Badgett D, Durfee J, Hussein S, Feichter J, Patrick K, Benedict R, Ramanathan M (2007): Immune cell BDNF secretion is associated with white matter volume in multiple sclerosis. J Neuroimmunol $\underline{188}$, 167-174

Wu X, Jiang X, Marini AM, Lipsky RH (2005): Delineating and understanding cerebellar neuroprotective pathways: potential implication for protecting the cortex. Ann N Y Acad Sci $\underline{1053}, 39-47$

Yamada J, Okabe A, Toyoda H, Kilb W, Luhmann HJ, Fukuda A (2004): Cl-uptake promoting depolarizing GABA actions in immature rat neocortical neurones is mediated by NKCC1. J Physiol 557(Pt 3), 829-841

Zafra F, Castren E, Thoenen H, Lindholm D (1991): Interplay between glutamate and yaminobutyric acid transmitter systems in the physiological regulation of brain-derived neurotrophic factor and nerve growth factor synthesis in hippocampal neurons. Proc Natl Acad Sci U S A $\underline{88}, 10037-10041$

Zhang X, Mei Y, Liu C und Yu S (2007): Effect of transcranial magnetic stimulation on the expression of c-Fos and brain-derived neurotrophic factor of the cerebral cortex in rats with cerebral infarct. J Huazhong Univ Sci Technolog Med Sci $\underline{4}$, 415-418

Ziemann U, Iliać TV, Pauli C, Meintzschel F, Ruge D (2004): Learning modifies subsequent induction of long-term potentiation-like and longterm depression-like plasticity in human motor cortex. J Neurosci 24, 1666-1672

Ziemann U, Paulus W, Nitsche MA, Pascual-Leone A, Byblow WD, Berardelli A, Siebner HR, Classen J, Cohen LG, Rothwell JC (2008): Consensus: motor cortex plasticity protocols. Brain Stim 1, 164-182

Zivadinov R, Weinstock-Guttman B, Benedict R, Tamaño-Blanco M, Hussein S, Abdelrahman N, Durfee J, Ramanathan M (2007): Preservation of gray matter volume in multiple sclerosis patients with the Met allele of the rs6265 (Val66Met) SNP of brain-derived neurotrophic factor. Hum Mol Genet 16(22),2659-2668

Zoladz JA, Pilc A, Majerczak J, Grandys M, Zapart-Bukowska J, Duda K (2008): Endurance training increases plasma brain-derived neurotrophic factor concentration in young healthy men. J Physiol Pharmacol Suppl $\underline{59}(7), 119-32$ 


\section{Teilnehmerinformation}

Zentrum Neurologie

Abteilung Klinische Neurophysiologie (Prof. Dr. W. Paulus)
Abt. Klin. Neurophysiologie

Leiter: Prof. Dr. W. Paulus

Robert-Koch-Str. 40

37075 Göttingen

Telefon: +49 551 39-6650/52

Telefax: +4955139-8126

e-mail: w.paulus@med.unigoettingen.de

Az: Prof. P/Rie

Durchwahl: 0551/39-6650

Datum: 08.01.2008

\section{ProbandenInformation}

Molekulargenetische Analysen zur Aufklärung der Neuroplastizität

Sehr geehrte Teilnehmerin, sehr geehrter Teilnehmer!

Wir möchten Sie bitten, an o.g. wissenschaftlicher Untersuchung teilzunehmen und möchten Ihnen den Ablauf der Studie anhand dieses Informationsbogens erläutern. Sie selbst werden nicht unmittelbar von dieser Studie profitieren, die Ergebnisse ermöglichen es uns jedoch, weiterführende Erkenntnisse über Neuroplastizität zu gewinnen.

Neuere experimentelle Arbeiten weisen auf den Zusammenhang zwischen den Varianten eines bestimmten Genes und neuroplastischen Mechanismen zur Begrenzung synaptischer Modifizierbarkeit in Gehirn hin. Deshalb möchten wir Sie bitten, an einer klinischen Studie teilzunehmen, bei der wir für molekulargenetische Untersuchungen bei Ihnen einmalig $7 \mathrm{ml}$ Blut abnehmen wollen. Aus den im Blut enthaltenen Blutzellen wird DNS (Träger der Erbsubstanz) isoliert und für weitere Untersuchungen gelagert.

Die Studienteilnahme ist freiwillig. Sie haben das Recht, Ihre Einwilligung jederzeit ohne Angabe von Gründen zu wiederrufen, ohne dass Ihnen Nachteile auf Ihre weitere Behandlung entstehen.

Es werden nur molekulargenetische Untersuchungen, die im Zusammenhang mit der Neuroplastizität stehen, durchgeführt. Alle Daten werden so gespeichert, dass Dritte sie nicht einsehen können. Daneben unterliegen alle Daten der ärztlichen Schweigepflicht. Die Blutproben werden durch den Studienarzt mit Hilfe einer Zahlencodierung anonymisiert und nur dieser hat Zugriff auf die Codierung. Damit ist eine Identifizierung Ihrer Person durch Dritte nicht mehr möglich. Die Blutproben werden zur Analyse 
verschickt und dort ausgewertet und aufbewahrt. Die Daten werden in anonymisierter Form wissenschaftlich ausgewertet. Es werden keine individuellen Informationen über persönliche Ergebnisse, die im Rahmen der wissenschaftlichen Untersuchung gewonnen werden, weitergegeben. Die Ergebnisse unserer gesamten wissenschaftlichen Untersuchung und der Zusammenhang zwischen Ihrem Genotyp und neuroplastischen Mechanismen werden Ihnen aber auf Anfrage gerne mitgeteilt. Für Auskünfte und Informationen stehen wir in gegebenen Fällen zusammen mit der Abteilung Humangenetik, in der dortigen Beratungsstelle, gerne zur Verfügung.

Prof. Dr. med. W. Paulus

Leiter der Abteilung

Klinische Neurophysiologie

PD Dr. rer. nat. Andrea Antal

Klinische Neurophysiologie 


\section{Zentrum Neurologie}

Abteilung Klinische Neurophysiologie (Prof. Dr. W. Paulus)

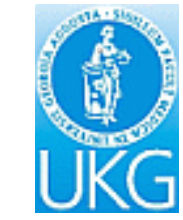

Abt. Klin. Neurophysiologie

Leiter: Prof. Dr. W. Paulus

Robert-Koch-Str. 40

37075 Göttingen

Telefon: +49551 39-6650/52

Telefax: +4955139-8126

Einverständniserklärung zur molekularbiologischen Analyse und Aufbewahrung von Untersuchungsmaterial

e-mail:w.paulus@med.uni-

goettingen.de

Az: Prof. P/Rie

Durchwahl: 0551/39-6650

Datum: 08.01.2008

Herr/Frau Dr.

hat mir heute, anhand der

Hinweise auf dem Informationsbogen für Teilnehmer an o.g. Studie, die Durchführung der Untersuchung erläutert. Ich habe diesbezüglich keine weiteren Fragen mehr und willige hiermit in die dargestellten Untersuchungen ein. Alle mich interessierenden Fragen wurden ausreichend beantwortet. Ich erkläre darüber hinaus, daß ich alle Angaben zur Krankengeschichte wahrheitsgemäß gemacht habe.

Ich erkläre mich einverstanden, dass von mir entnommenes Blut im Rahmen eines Forschungsprojekts zur Aufklärung des Zusammenhanges zwischen Varianten eines bestimmten Genes und neuroplastischen Mechanismen untersucht wird und dass das Untersuchungsmaterial aufbewahrt wird. Falls in diesem Zusammenhang weitere Genvarianten in Zukunft untersucht werden können, erteile ich auch hierfür meine Zustimmung.

Ich bin darüber informiert worden und damit einverstanden, dass meine Daten auf Papier und elektronisch zum Zwecke der wissenschaftlichen Auswertung gespeichert werden. Dies bezieht sich ausschließlich auf Gesundheitsdaten, die zum Zwecke dieser Studie erforderlich sind. Mir ist bekannt, daß ich jederzeit ohne Angabe von Gründen die weitere Untersuchung ablehnen bzw. meine Einverständniserklärung widerrufen kann, ohne daß mir daraus Nachteile entstehen. Bei Rücknahme meines Einverständnisses werden diese Daten gelöscht und die gelagerte DNA wird daraufhin vernichtet. Alle Regeln des Datenschutzes werden berücksichtigt.

Ich bin bereit, an der Studie teilzunehmen.

Eine Kopie dieser Erklärung wurde mir überreicht.

Göttingen, den

Name des aufklärenden Arztes (in Druckbuchstaben) und Unterschrift

Name des Probanden (in Druckbuchstaben) und Unterschrift 


\section{Danksagung}

Ich möchte mich an dieser Stelle bei meiner Doktormutter, Frau Prof. Dr. rer. nat. Andrea Antal, ganz herzlich bedanken, die mir immer ihre Hilfe angeboten hat. Sowohl bei der Durchführung der Arbeit als auch bei der Abfassung der Doktorarbeit hat sie mir Beistand geleistet. Ihre konstruktive und freundliche Betreuung hat mich immer wieder zu neuen Gedanken angeregt.

Danken möchte ich auch Prof. Dr. med. Paulus, dem Leiter der Abteilung Klinische Neurophysiologie. 